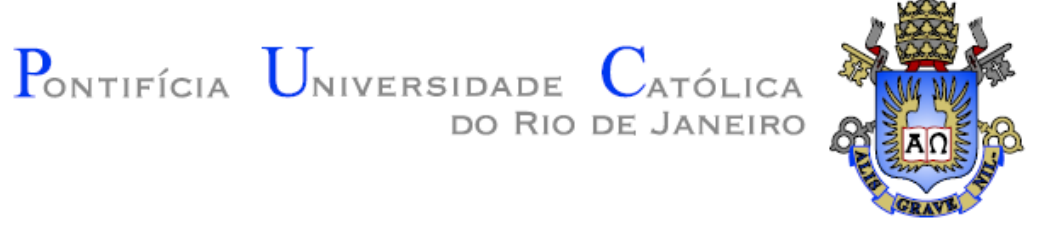

Inaê Rodrigues de Almeida

\begin{abstract}
Escoamento de fluido não newtoniano em espaço anular excêntrico com rotação do cilindro interno
\end{abstract}

Dissertação de Mestrado

Dissertação apresentada ao Programa de Pósgraduação em Engenharia Mecânica da PUC-Rio como requisito parcial para obtenção do título de Mestre em Engenharia Mecânica.

Orientador: Márcio da Silveira Carvalho 
Inaê Rodrigues de Almeida

\title{
Escoamento de fluido não newtoniano em espaço anular excêntrico com rotação do cilindro interno
}

\begin{abstract}
Dissertação apresentada como requisito parcial para obtenção do grau de Mestre pelo Programa de Pósgraduação em Engenharia Mecânica da PUC-Rio. Aprovada pela Comissão Examinadora abaixo assinada.
\end{abstract}

\author{
Prof. Márcio da Silveira Carvalho \\ Orientador \\ Departamento de Engenharia Mecânica - PUC-Rio
}

Prof. Paulo Roberto de Souza Mendes

Departamento de Engenharia Mecânica - PUC-Rio

\author{
Dr. Geraldo Afonso Spinelli Martins Ribeiro \\ Petróleo Brasileiro S.A.- Petrobras
}

Prof. José Eugenio Leal

Coordenador Setorial do Centro Técnico Científico - PUC-Rio

Rio de Janeiro, 14 de maio de 2012 
Todos os direitos reservados. É proibida a reprodução total ou parcial do trabalho sem autorização do autor, do orientador e da universidade.

\section{Inaê Rodrigues de Almeida}

Graduou-se em Engenharia Química pela Universidade Federal Fluminense - UFF (Rio de Janeiro, Brasil) em 2002. Pós-graduada em Engenharia de petróleo e gás natural na Universidade Federal Fluminense - UFF em 2005. Pósgraduada em Engenharia de Petróleo na CCE/PUC-Rio em 2007. Atua como engenheira de petróleo de produção na Statoil desde 2010.

Ficha Catalográfica

Almeida, Inaê Rodrigues de
Escoamento de fluido não Newtoniano em espaço
anular excêntrico com rotação do cilindro interno / Inaê
Rodrigues de Almeida; orientador: Márcio da Silveira
Carvalho - Rio de Janeiro: PUC, Departamento de
Engenharia Mecânica, 2012 .
v., 70 f.: il. (color); $30 \mathrm{~cm}$
1. Dissertação (mestrado) - Pontifícia Universidade
Católica do Rio de Janeiro, Departamento de Engenharia
Mecânica, Rio de Janeiro, 2012.
Inclui referências bibliográficas.
1. Engenharia Mecânica - Teses. 2. Teoria da
lubrificação. 3. Espaço anular. 4. Fluido não Newtoniano. 5.
Excentricidade constante. 6. Rotação do cilindro interno. 7.
Escoamento de fluido de perfuração I. Carvalho, Márcio da
Silveira. II. Pontifícia Universidade Católica do Rio de
Janeiro. Departamento de Engenharia Mecânica. III. Título.

CDD: 621 
Dedico este trabalho aos meus pais, mestres da minha vida 


\section{Agradecimentos}

Ao meu Orientador Professor Doutor Marcio da Silveira Carvalho que me ajudou a superar todos os obstáculos deste trabalho com serenidade e sabedoria.

À PUC-Rio, pelos auxílios concedidos, possibilitando a realização deste trabalho.

Aos professores do Departamento de Engenharia Mecânica que ao longo do mestrado contribuíram para minha formação acadêmica.

Aos funcionários do Departamento de Engenharia Mecânica, em especial a Roseli, pelo apoio administrativo ao longo destes anos.

Ao mentor e amigo Geraldo Spinelli que muito contribuiu no desenvolvimento da minha carreira no mercado de petróleo, e inspirou o desafio do mestrado.

Aos meus pais, pelo amor incondicional dedicado todos os anos da minha vida, e exemplo de caráter e perseverança que me tornaram a pessoa que sou hoje.

Ao João Marcelo pelo amor, carinho e companheirismo durante os anos vividos juntos, e a paciência durante os anos dedicados ao mestrado.

Aos meus amigos Guilherme e Marisa pelas palavras de apoio e motivação concedidas nos momentos difíceis. 


\section{Resumo}

Almeida, Inaê Rodrigues de; Carvalho, Márcio da Silveira. Escoamento de fluido não newtoniano em espaço anular excêntrico com rotação do cilindro interno. Rio de Janeiro, 2012. 70 p. Dissertação de Mestrado Departamento de Engenharia Mecânica, Pontifícia Universidade Católica do Rio de Janeiro.

O presente trabalho apresenta um modelo simplificado baseado na teoria de lubrificação e conceito de viscosidade equivalente para estudar o escoamento dos fluidos de perfuração através de um espaço anular excêntrico com rotação da coluna de perfuração. Em razão do comportamento não Newtoniano destes fluidos, é significativa a influência da rotação da coluna na perda de carga, já que a viscosidade dos fluidos varia com a taxa de deformação imposta. Uma completa análise deste problema requer uma solução tridimensional da equação de conservação de quantidade de movimento de fluidos não Newtonianos, cuja solução é extremamente cara computacionalmente, tornando necessário o desenvolvimento de modelos simplificados que descrevam bem os principais fenômenos observados nestes escoamentos. No modelo proposto, as equações que governam o escoamento são simplificadas pela teoria da lubrificação em coordenadas cilíndricas. Desta forma, o escoamento tridimensional é descrito por uma única equação diferencial bidimensional para o campo de pressão. O comportamento mecânico do fluido é avaliado através do método da Viscosidade Newtoniana Equivalente. O modelo proposto foi validado a partir de soluções numéricas para o modelo completo, disponíveis na literatura, avaliando a precisão das simplificações adotadas. Os resultados mostram o intervalo no qual o modelo simplificado é preciso e apresentam o efeito das propriedades dos fluidos, da geometria do poço e da rotação da coluna na perda de carga do escoamento.

\section{Palavras-chave}

Teoria da lubrificação; espaço anular; fluido não Newtoniano; excentricidade constante; rotação da coluna; escoamento de fluido de perfuração. 


\section{Abstract}

Almeida, Inaê Rodrigues de; Carvalho, Márcio da Silveira (Advisor). Non newtonian flow in eccentric annular space with rotating inner cylinder. Rio de Janeiro, 2012. 70 p. MSc. Dissertation - Departamento de Engenharia Mecânica, Pontifícia Universidade Católica do Rio de Janeiro.

In this work a simplified model based on the Lubrication Theory and on the equivalent viscosity is presented to study the drilling fluid flow dynamics through an eccentric annular space with rotation of the drilling column. As a result of the non-Newtonian behavior of the fluid, the rotation of the column has a significant impact on the pressure drop since the viscosity of the fluids is a function of the strain rate applied. A complete analysis of this problem requires a tridimensional solution of the equation of momentum conservation, which makes the solution computationally expensive. For such, simplified accurate models that describe the main phenomena observed have to be developed. On the proposed model, the flow dynamics equations are simplified by the Lubrication Theory in cylindrical coordinates. Therefore, the tridimensional flow is described by one single two dimensional equation for the pressure field. The mechanical behaviour of the fluid is evaluated through the Equivalent Newtonian Viscosity method. The proposed model, as well as the accuracy of the simplifications used, was validated by comparison with numerical solutions of the complete set of equations available on the literature. The results show the range in which the proposed simplified model is accurate and presents the effects of the fluids properties, well geometry and column rotation on the pressure loss.

\section{Keywords}

Lubrication Theory; annular space; non-Newtonian fluid; constant eccentricity; rotating column; mud flow. 


\section{Sumário}

1 Introdução 12

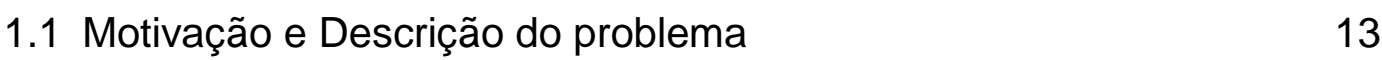

$\begin{array}{lr}1.2 \text { Revisão Bibliográfica } & 19\end{array}$

$\begin{array}{ll}1.3 \text { Proposta e Objetivo } & 26\end{array}$

2 Modelo 28

2.1 Geometria 28

2.2 Escoamento não Newtoniano 30

2.3 Teoria da Lubrificação 33

2.4 Método da Viscosidade Newtoniana Equivalente 38

2.5 Solução do Modelo 43

3 Resultados $\quad 48$

3.1 Parâmetros Adimensionais 48

3.2 Validação do modelo para caso Concêntrico 50

3.3 Validação do modelo para caso Excêntrico 52

3.4 Efeitos da razão de raios no escoamento 57

3.5 Efeitos da excentricidade no escoamento 58

3.6 Efeitos da Rotação do cilindro interno no escoamento 60

4 Considerações Finais $\quad 67$

5 Referências Bibliográficas $\quad 69$ 


\section{Lista de figuras}

Figura 1 - Retorno de fluido e cascalho pelo anular [1] .......................... 13

Figura 2 - Coluna de perfuração durante a operação [2] .......................... 14

Figura 3 - Tipos de Flambagem [3] ............................................... 15

Figura 4 - Movimentação de cascalhos em um poço horizontal [3]..........16

Figura 5 - Relação entre limpeza de poço e rotações da coluna [3]......... 16

Figura 6 - Esquema do sistema de circulação [6]...................................17

Figura 7 - Sistema de tratamento do fluido de perfuração [4] .................. 18

Figura 8 - Espaço anular com excentricidade constante ...........................29

Figura 9 - Configuração da seção transversal........................................29

Figura 10 - Curva de Viscosidade de Fluido: (A) Newtoniano; (B)

plástico ideal ou Binghamiano; (C) pseudoplástico; e (D) dilatante [24]...30

Figura 11 - Curva de Fluxo do fluido de Power-law ou de Potência: I, II, III pseudoplásticos com $0<n<1$; a, b, c, dilatantes com $n>1$ [24] .............. 32

Figura 12 - Rotação do cilindro interno em espaço anular excêntrico...... 40

Figura 13 - Rotação do cilindro interno em espaço anular excêntrico...... 44

Figura 14 - Ilustração gráfica da regra do trapézio.................................. 45

Figura 15 - llustração do processo iterativo do modelo proposto..............47

Figura 16 - Influência da excentricidade no comportamento do produto $f$. Re em fluidos não Newtonianos e sem rotação do cilindro interno. ......53

Figura 17 - Influência da excentricidade no comportamento do produto f. Re em fluidos não Newtonianos com rotação do cilindro interno ( $\mathrm{Ta}=$ 10).

Figura 18 - Influência da excentricidade no comportamento do produto $f$. Re em fluidos não Newtonianos com rotação do cilindro interno $(\mathrm{Ta}=$ 100).

Figura 19 - Influência da excentricidade no comportamento do produto $f$. Re em fluidos não Newtonianos com rotação do cilindro interno ( $\mathrm{Ta}=$ 1000). 
Figura 20 - Influência da excentricidade no comportamento do produto $f$. Re em fluidos não Newtonianos com rotação do cilindro interno $(\mathrm{Ta}=$ 10000)

Figura 21 - Influencia da razão de raios no produto $f$. Re para

escoamento de fluido com comportamento não Newtoniano.

Figura 22 - Influencia da excentricidade no produto $f$. Re, e diferentes razões de raios $(k)$.

Figura 23 - Influencia da excentricidade no produto $f$. Re para fluidos com diferentes índices de potência $(n)$.

Figura 24 - Influencia da excentricidade no produto $f$. Re de um fluido não Newtoniano $(n=0,5)$. 60

Figura 25 - Escoamento de um fluido Newtoniano em espaço anular concêntrico com rotação do cilindro interno, para diferentes razões de raios $(k)$

Figura 26 - Escoamento de um fluido Newtoniano em espaço anular concêntrico com rotação do cilindro interno, para diferentes razões de raios $(k)$. 62

Figura 27 - Influencia da rotação do cilindro interno e da razão de raios $(k)$ no escoamento de um fluido Newtoniano 63

Figura 28 - Influência da rotação no comportamento do escoamento.......64

Figura 29 - Variação da relação $f$. Re com Ta em anular concêntrico.......64

Figura 30 - Variação da relação $f$. Re com Ta e excentridade constante $(e=0,4)$

Figura 31 - Variação da relação $f$. Re com Ta e excentridade constante $(e=0,9)$

Figura 32 - Variação da relação $f$. Re com Ta para fluidos não

Newtonianos em espaço anular concêntrico e mesma razão de raios $(k=0,5)$ 


\section{Lista de tabelas}

Tabela 1 - Funções Viscosidade e parâmetros reológicos de fluidos

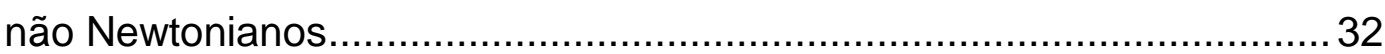

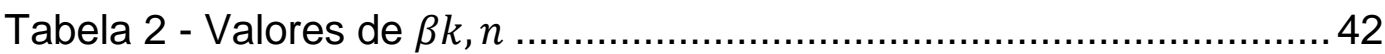

Tabela 3 - Solução concêntrica para Fluido Newtoniano $n=1 \ldots \ldots \ldots \ldots \ldots . . .51$

Tabela 4 - Solução concêntrica para Fluido não Newtoniano ...................52

Tabela 5 - Solução com espaço anular excêntrico para Fluido não

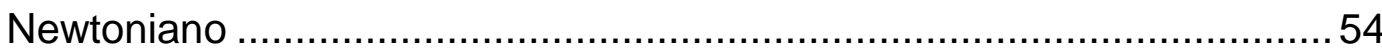

Tabela 6 - Solução com espaço anular excêntrico para Fluido não

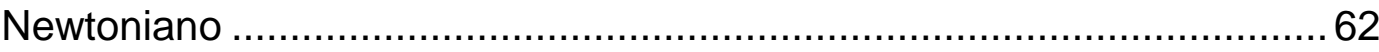




\section{1 \\ Introdução}

Ao se perfurar um poço de petróleo, é produzida instabilidade em um sistema que se encontrava equilibrado. Conhecer os fenômenos envolvidos, quantificar sua intensidade e minimizar seus efeitos nas operações realizadas constitui-se um grande desafio para a engenharia de perfuração de poços de petróleo.

A maioria dos fluidos envolvidos nos processos de perfuração apresenta um comportamento não Newtoniano, com a viscosidade dependente da cinemática do escoamento. Assim, ao longo de um escoamento isotérmico, o fluido apresentará diferentes níveis de viscosidade. Obviamente, este comportamento torna a análise dos escoamentos bem mais complexa do que no caso Newtoniano, que por si só já é bastante complexo, envolvendo efeitos da rotação da coluna de perfuração e da excentricidade do espaço anular, que pode variar ao longo do poço.

Uma completa análise deste problema requer uma solução tridimensional da equação de conservação de quantidade de movimento, a qual seria muito complexa e cara do ponto de vista computacional. Contudo, a busca pela otimização do processo de perfuração motivou diversos autores a realizarem estudos experimentais e numéricos com soluções aproximadas para o escoamento, os quais estão disponíveis na literatura, como poderá ser observado na revisão bibliográfica realizada como parte deste trabalho. No entanto, esses modelos apresentam simplificações que comprometem a sua precisão em determinadas situações. 


\section{1 Motivação e Descrição do problema}

$\mathrm{Na}$ indústria do petróleo, é crescente a busca por novas tecnologias a fim de tornar os processos mais eficientes. Devido às condições adversas, como o cenário de águas profundas e óleos pesados, a perfuração de poços de geometria complexa está sendo cada dia mais frequente.

Dentre os tipos de perfuração existentes, a perfuração rotativa é a mais utilizada, onde as rochas são atravessadas pela ação da rotação e peso aplicados a uma broca existente na extremidade da coluna de perfuração. Este método motivou a utilização do fluido de perfuração no auxílio da limpeza do poço, através do transporte de fragmentos da rocha, ou cascalhos, conforme representado na Figura 1.

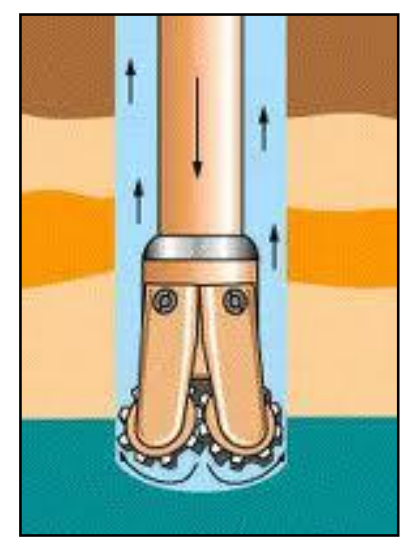

Figura 1 - Retorno de fluido e cascalho pelo anular [1]

Sendo assim, o escoamento do fluido de perfuração se torna muito importante, uma vez que a ineficiência na remoção dos cascalhos contidos dentro do espaço anular pode dificultar o processo de perfuração (diminuindo a taxa de penetração da broca), e até mesmo interrompê-lo, já que pode ocorrer prisão da coluna de perfuração, necessitando operações secundárias de pescaria.

Outro fator a ser considerado na caracterização do comportamento dos fluidos de perfuração é a dificuldade de posicionar a coluna de perfuração no centro do poço. Esta é uma operação complicada devido os vários esforços dinâmicos aos quais a coluna de perfuração está sujeita, tais como flexão, torção, força normal, e força cortante, onde sua rigidez estrutural, bem como as forças de 
reação resultantes da interação entre a coluna e a formação são responsáveis pela trajetória do poço. A Figura 2 ilustra a trajetória do poço sob os vários esforços dinâmicos durante uma operação de perfuração.

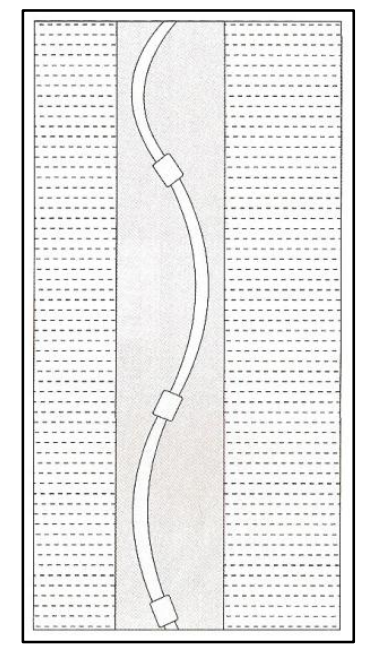

Figura 2 - Coluna de perfuração durante a operação [2].

No caso da perfuração de poços direcionais, horizontais ou de grandes afastamentos a coluna de perfuração tende a se posicionar mais perto da parte inferior da parede do poço devido os efeitos gravitacionais, resultando em uma excentricidade variável ao longo do anular.

Este fenômeno é conhecido como flambagem da coluna de perfuração e é comum em poços direcionais. Se a flambagem for do tipo senoidal normalmente é controlável, entretanto a do tipo helicoidal é considerada um caso extremo e sem solução contornável para o problema. O projeto do fluido de perfuração com lubricidade adequada irá auxiliar na prevenção da flambagem. A Figura 3 apresenta um esquema dos tipos de flambagem mencionados acima.

Devido à complexidade envolvida no planejamento de poços direcionais, deve-se prever o uso de fluido de perfuração com algumas características imprescindíveis, como tixotropia, alta lubricidade e baixa reatividade química com as rochas para que se tenha um melhor desempenho associado a uma redução do custo de operação.

De uma maneira geral, os fluidos de perfuração desempenham várias funções durante a fase de perfuração, entre os quais o transporte dos fragmentos 
da rocha perfurada até a superfície (limpeza do poço), a manutenção dos sólidos em suspensão em vazões muito baixas ou durante as paradas de circulação (tixotropia), a lubrificação e resfriamento da broca, a sustentação das paredes do poço e a contenção dos fluidos no reservatório (óleo, gás ou água).

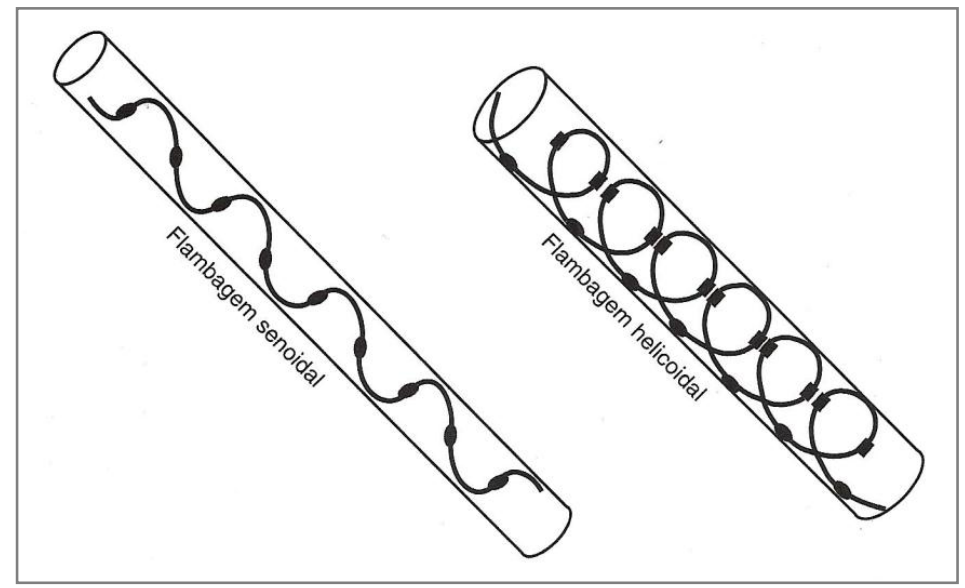

Figura 3 - Tipos de Flambagem [3].

Para conseguir cumprir todas estas funções, o fluido de perfuração deve apresentar algumas características: ser estável quimicamente; estabilizar as paredes do poço, mecânica e quimicamente; facilitar a separação dos cascalhos na superfície; manter os sólidos em suspensão quando estiver em repouso; ser inerte com as rochas produtoras; ser capaz de aceitar tratamento físico e/ou químico; ser passível de bombeamento; e ainda apresentar baixo grau de corrosão e abrasão em relação à coluna de perfuração, além de não ser agressivo ao meio ambiente [4].

Em muitas situações, apenas o uso da vazão para a limpeza do poço pode ser ineficaz, exigindo rotação da coluna de perfuração, notadamente em poços horizontais ou desviados. O intuito de se girar a coluna é mover o cascalho depositado na parte baixa do poço para cima, de modo a colocá-lo no fluxo de fluido e assim fazer com que ele siga em direção à superfície (Figura 4). 


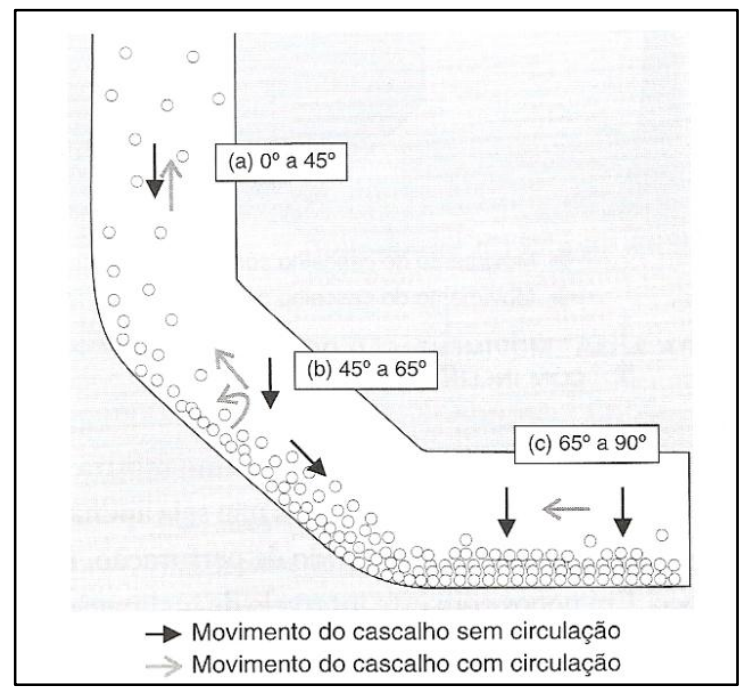

Figura 4 - Movimentação de cascalhos em um poço horizontal [3].

A Figura 5 mostra uma relação entre a velocidade de rotação da broca/coluna e a limpeza do poço, cuja distribuição de cascalhos e o leito formado ao longo do poço não causam problemas para a operação em andamento. Note que maiores rotações (RPM) significam melhor limpeza do poço, e, em poços de grande afastamento, existem alguns pontos de RPM, (a) e (b), onde a limpeza acentua-se mais rapidamente [3].

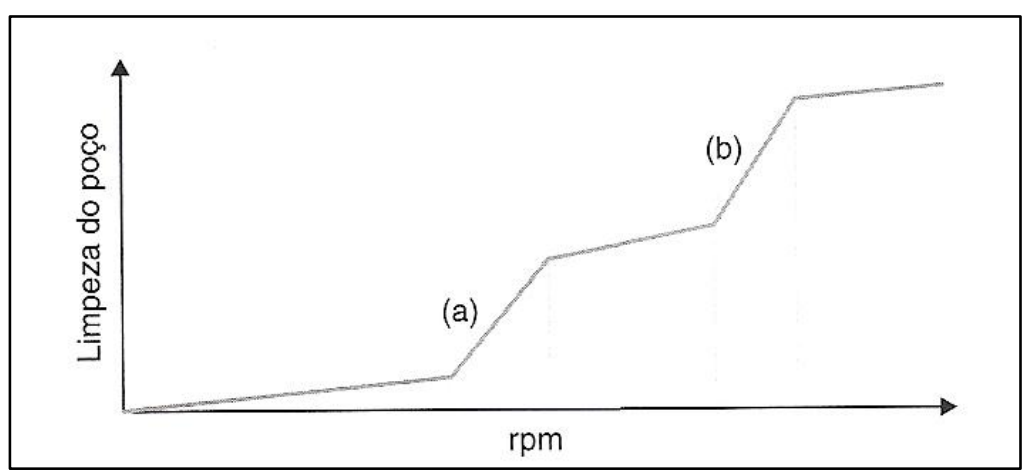

Figura 5 - Relação entre limpeza de poço e rotações da coluna [3].

A Figura 6 representa o sistema de circulação para manter o escoamento do fluido de perfuração durante toda a operação de perfuração do poço. O fluido é bombeado para o interior da coluna de perfuração através da cabeça de injeção, ou swivel, saindo pelos orifícios da broca, e retornando pelo espaço anular formado pelas paredes do poço e a coluna. O sistema de tratamento na superfície é composto por peneiras vibratórias, degaseificadores, desaeradores, desiltadores, centrífugas e mud cleaner (Figura 7). A separação é feita de forma a descartar os 
gases e sólidos inertes gerados no fundo do poço, preservando os aditivos químicos presentes no fluido de perfuração [5].

Devido a aspectos de dimensionamento, segurança e eficiência do sistema de circulação, é importante se conhecer a pressão e perfil de velocidades em cada ponto do circuito. Desta forma, torna-se necessário a modelagem do escoamento considerando-se aspectos relativos a regimes de fluxo, reologia do fluido, condições de operação (geometria do sistema, vazão nas bombas, rotação da coluna, taxa de penetração) e condições ambientais (temperatura, pressão).

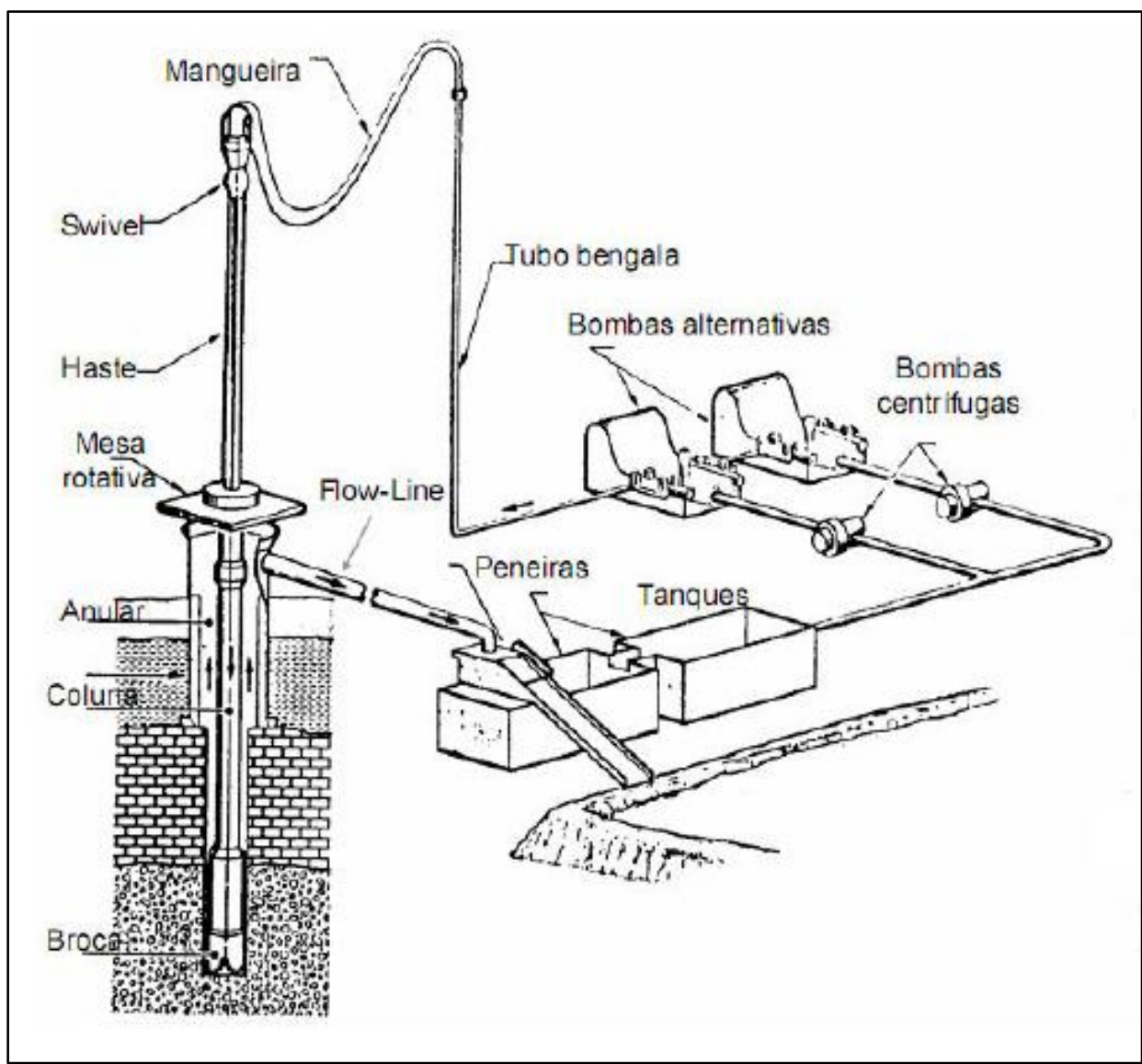

Figura 6 - Esquema do sistema de circulação [6]. 


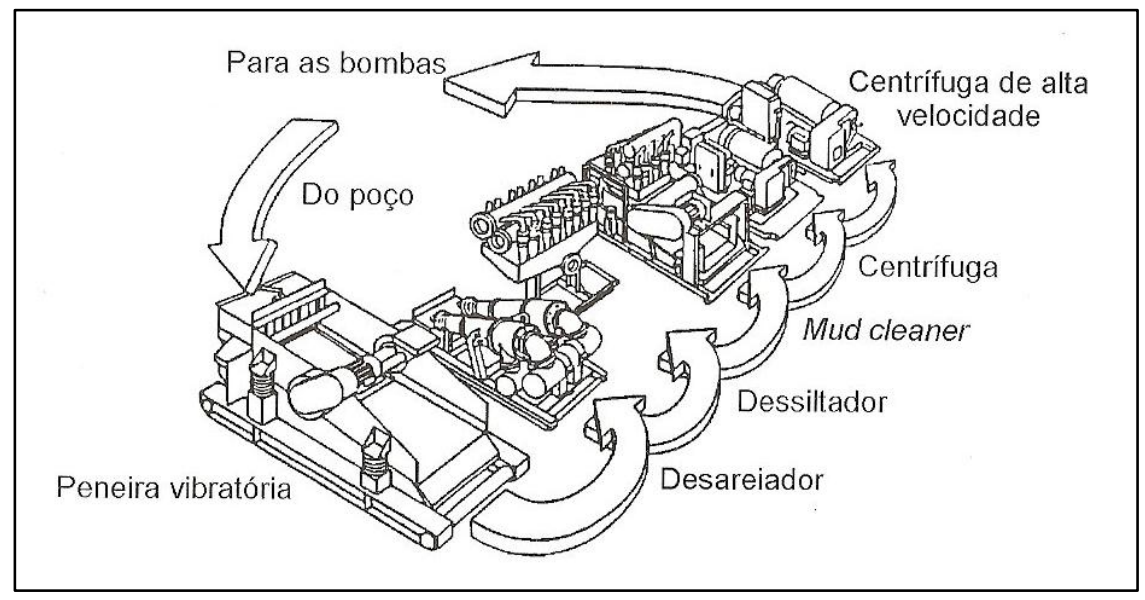

Figura 7 - Sistema de tratamento do fluido de perfuração [4].

Uma completa análise dos parâmetros do escoamento do fluido de perfuração durante a operação de perfuração é extremamente complexa, envolvendo fluidos não Newtonianos, geometria com excentricidade variável em espaço anular, rotação da coluna de perfuração e eficiência no transporte de cascalhos até a superfície.

A fim de se obter uma estimativa realista do comportamento dos cascalhos em um anular com excentricidade variável, é necessária a inclusão da análise do perfil de velocidades do fluido nos vários níveis de excentricidade no modelo de escoamento. Da mesma forma, um aumento de viscosidade do fluido de perfuração deve ser considerado devido à incorporação dos cascalhos liberados durante a penetração da broca na formação rochosa. A relação destas propriedades físicas em conjunto com a tensão de cisalhamento e taxa de cisalhamento podem afetar a eficiência da operação de perfuração.

Outro parâmetro que pode afetar o escoamento é a rotação da coluna de perfuração. O comportamento não Newtoniano dos fluidos de perfuração leva a uma influência muito grande da rotação da coluna na perda de carga, já que a mesma pode aumentar consideravelmente a taxa de cisalhamento do escoamento e, consequentemente, causar alteração da viscosidade do líquido.

O escoamento na região anular com rotação do cilindro interno é um problema clássico na mecânica dos fluidos, e amplamente estudado. Devido à complexidade computacional das equações diferenciais de conservação e quantidade de movimento, diversas análises estão disponíveis na literatura 
considerando diferentes simplificações e abordagens para o mesmo problema. Alguns destes resultados de modelagens matemáticas para previsão de perdas de carga e perfis de velocidade, bem como medidas experimentais em laboratório serão revistos na próxima seção.

\section{2 Revisão Bibliográfica}

Vaughn [7], no ano de 1965, analisou o escoamento laminar do fluido não Newtoniano descrito pelo modelo de potência (Power-law) em anular estreito e excêntrico a fim de discutir os erros introduzidos pela excentricidade em análises experimentais utilizando-se anulares concêntricos. Uma relação entre as vazões volumétricas em anulares concêntricos e excêntricos foi obtida através de um modelo para escoamento entre duas placas paralelas. No caso dos fluidos Newtonianos, o erro observado com o aumento da excentricidade não foi significativo, ao contrário dos fluidos plásticos e pseudoplásticos que apresentaram um aumento significativo da vazão volumétrica com o aumento da excentricidade. A perda de carga nos fluidos pseudoplásticos, para uma dada vazão volumétrica, apresentou uma redução não significativa com o aumento da excentricidade.

No ano de 1981, Iyoho e Azar [8] desenvolveram um modelo matemático de fluido Power-law, em geometria de ranhura não retangular, para obtenção de soluções analíticas do perfil de velocidade de um fluido não Newtoniano em anular excêntrico. O perfil de velocidade foi determinado utilizando-se as equações obtidas por Vaughn [7], mas levando-se em consideração a dependência das razões dos diâmetros dos cilindros. Os resultados indicaram que o aumento da excentricidade nas regiões mais estreitas é acompanhado de diminuição da velocidade, enquanto nas regiões com maior espaçamento ocorre aumento da velocidade. Os autores concluíram que este método é adequado para aplicação nas operações de perfuração sem afetar a precisão dos resultados, não requerendo transformação matemática ou computações iterativas. 
Já no ano de 1989, Pinho e Whitelaw [9] estudaram os resultados da velocidade média axial e das três tensões normais obtidas em fluxo desenvolvido. A intenção do estudo era quantificar os benefícios dos fluidos não Newtonianos na redução da resistência ao fluxo. O experimento foi conduzido com um fluido não Newtoniano, identificando a velocidade média em função das diferentes concentrações de polímero, diferentes vazões, e uma faixa de número de Reynolds. Os resultados quantificaram um atraso na transição do escoamento laminar para o turbulento causado pelo comportamento pseudoplástico do fluido, assim como a supressão de flutuações do escoamento turbulento particularmente nas componentes radial e tangencial da tensão normal, e uma redução da resistência ao fluxo em presença de altos números de Reynolds. $\mathrm{O}$ experimento confirmou que as considerações para a redução máxima de resistência são apropriadas para as soluções pseudoplásticas.

No mesmo ano, Uner et al [10] ampliaram o estudo realizado por Iyoho e Azar [8], calculando a vazão volumétrica através da versão modificada da equação de Skelland. Esta equação foi originalmente desenvolvida para a aplicação em fluxos com anular concêntrico, e não é apropriada nos casos de aumento de excentricidade e razão dos raios dos cilindros. A solução encontrada pelos autores para melhor refletir o efeito da excentricidade foi considerar o espaço anular excêntrico como uma aproximação de uma fenda com altura variável. Os valores obtidos indicaram que o decréscimo do índice Power-law e o aumento da excentricidade resultam em um aumento da vazão volumétrica quando a diferença de pressão permanece constante. A análise da razão das vazões volumétricas para anulares concêntricos e excêntricos, sob a mesma queda de pressão, comprovou a influência da excentricidade na vazão volumétrica, especialmente nos casos de baixo índice Power-law.

Luo e Peden [11], no ano de 1990, desenvolveram um modelo matemático para o escoamento em anular excêntrico considerando infinitos números de anulares concêntricos com diferentes valores de raio do cilindro externo. Utilizando este método o autor desenvolveu soluções analíticas para tensão de cisalhamento, taxa de cisalhamento, perfil de velocidade, vazão volumétrica e gradiente de pressão, aplicadas aos fluidos Power-law e Bingham. Neste estudo 
observou-se a variação do perfil de velocidade, bem como as magnitudes da taxa e tensão de cisalhamento, com a posição radial. Foi ressaltado pelo autor que no caso dos fluidos de Bingham pode-se observar fluxo somente em parte da área do anular excêntrico, ao contrário de um anular concêntrico. Isso irá depender do gradiente de pressão e excentricidade impostas ao anular. Os resultados demonstraram que a tensão de cisalhamento apresenta-se maior em magnitude nas áreas ampliadas do que nas áreas reduzidas do anular excêntrico. Uma comparação com os resultados obtidos pelos modelos de coordenadas bipolares e fenda mostrou melhores aproximações do modelo proposto para os casos de baixa excentricidade. Em compensação, nos casos com excentricidades intermediárias e altas o modelo de fenda apresenta melhor aproximação. Para ambos os fluidos, Power-law e Bingham, observou-se aumento da vazão volumétrica com o aumento da excentricidade e gradiente de pressão constante.

No ano de 1995, Cui e Liu [12] desenvolveram um modelo numérico utilizando o método de diferenças finitas para aplicação no estudo de fluxo helicoidal de um fluido não Newtoniano em anular excêntrico. As equações de continuidade e movimento foram utilizadas e considerou-se escoamento laminar com fluxo permanente e isotérmico de um fluido não Newtoniano. O modelo matemático mostrou-se preciso quando comparados seus resultados aos obtidos em laboratório pelos próprios autores em um experimento concluído em 1985. Os dados demonstraram que a rotação do cilindro interno em um anular excêntrico e o aumento desta excentricidade contribuem para o aumento da vazão de fluxo helicoidal. Observou-se a formação de um fluxo secundário próximo ao cilindro externo, na região de maior folga entre os cilindros, nos casos de maior excentricidade. Estes fatos observados podem ser explicados como resultado do comportamento do fluido não Newtoniano.

Siginer e Bakhtiyarov [13], no ano de 1997, investigaram de forma numérica e experimental o comportamento da viscosidade de fluidos não Newtonianos em anular excêntrico. As propriedades reológicas dos fluidos não Newtonianos foram descritas pelo modelo desenvolvido por Kutateladze et al [14], que estabelece a viscosidade como função da tensão de cisalhamento. A simplificação da teoria da Lubrificação em coordenadas cartesianas possibilitou as 
aproximações de geometria de canal com fenda e pressão constante ao longo do eixo azimutal. Com isso, a solução numérica do perfil de velocidade foi obtida e comparada com o perfil de velocidade medido experimentalmente através do método estroboscópico de visualização de fluxos. Os resultados experimentais corroboraram com os resultados obtidos numericamente, onde o modelo de viscosidade para fluidos não Newtonianos apresentou velocidades menores e uma maior área de fluxo turbulento quando comparados aos fluidos newtonianos. Em ambos os casos observou-se uma tendência de crescimento do fluxo turbulento com o aumento da excentricidade e comportamento não Newtoniano, o que reduz a eficiência das operações de unplugging.

No ano de 1999, Escudier et al [15], motivados pela influência dos fluidos nas operações de perfuração de poços, estudaram os efeitos de um escoamento laminar desenvolvido de um fluido Newtoniano através de um anular excêntrico combinado com rotação do cilindro interno. Para isso, as equações da continuidade e momento para três dimensões foram transformadas em um sistema coordenado não ortogonal geral para o cálculo das componentes da velocidade cartesiana. Observou-se influência da rotação do cilindro na velocidade axial refletida nas tensões de cisalhamento, nos cilindros externo e interno, bem como na perda de carga. Os estudos revelaram um aumento da perda de carga para altos valores de excentricidade com o aumento do número de Taylor, mantendo-se o número de Reynolds constante, ao contrário da esperada redução da perda de carga.

Já no ano de 2002, Escudier et al [16] prosseguiram com os estudos e analisaram de forma numérica o escoamento dos sistemas coloidais de líquidos pseudoplásticos, tixotrópicos, viscoelásticos e exibindo tensão de cisalhamento aparente. O modelo foi desenvolvido para aplicação nas operações de perfuração e as dificuldades enfrentadas no controle do posicionamento da coluna de perfuração, para análise das consequências desta excentricidade. Para efeitos de modelagem foi considerado um escoamento laminar de um líquido pseudoplástico, em fluxo permanente, isotérmico, através de um anular consistindo de um cilindro interno com rotação e excêntrico em relação ao cilindro externo. O campo de velocidade na seção foi obtido numericamente pelo 
método de volumes finitos. Foi realizado um estudo extensivo para os fluidos Power-law e estudado o efeito da aplicação de outros modelos reológicos (Herschel-Bulkley, Carreau e Cross). Em geral, os resultados obtidos para o fluido Power-law apresentaram menor perda de carga, mas com mesma tendência anteriormente observada para o fluido Newtoniano. Para valores baixos e muito altos de excentricidade observou-se aumento do produto $f$. Re com o aumento do número de Taylor, enquanto que para excentricidades intermediárias observou-se diminuição do produto $f$. Re com o aumento do número de Taylor. Nos casos de baixo número de Reynolds foi possível identificar um comportamento não reportado em nenhum estudo anterior, onde os valores de perda de carga poderiam exceder o valor correspondente para um fluido Newtoniano. Este fenômeno é consequência de um fluxo de recirculação na região próxima ao cilindro externo, resultando em uma tensão de cisalhamento alta e aumento do produto $f$.Re. A recirculação irá desaparecer para valores muito altos de rotação e grande afastamento do comportamento Newtoniano.

Hemphill e Ravi [17], no ano de 2005, investigaram os efeitos da rotação da coluna em anular concêntrico na velocidade axial de um fluido não Newtoniano. O modelo reológico de Herschel-Bulkley foi utilizado para o cálculo da taxa de cisalhamento através do anular, considerando-se os efeitos acoplados do escoamento laminar e rotação da coluna. Os resultados concluíram que na presença de fluxo axial os vórtices de Taylor são dissipados e seus efeitos podem ser negligenciados. A variação do diâmetro interno do poço possibilitou o estudo dos efeitos da rotação em diferentes espessuras de espaço anular, observando-se um aumento da vazão e gradiente de pressão nos casos de espaços anulares mais estreitos. O aumento da velocidade de rotação da coluna em regiões com baixa velocidade anular proporcionou os maiores aumentos na pressão de circulação. Entretanto, a baixas velocidades de rotação da coluna observou-se fenômeno contrário, com diminuição da pressão de circulação. Analisou-se o efeito do diâmetro do poço, e verificou-se que variações de tamanho afetam a perda de carga em todas as velocidades de rotação da coluna.

No ano seguinte, Hemphill e Ravi [18] ampliaram o estudo anterior de rotação de coluna em anular concêntrico e discutiram os efeitos da rotação da 
coluna de perfuração no perfil de velocidade e gradiente de pressão em anulares excêntricos. Os cálculos de gradiente de pressão foram realizados utilizando o modelo reológico de Herschel-Bulkley. Observou-se um aumento do gradiente de pressão com o aumento da rotação da coluna nos casos de menor vazão axial, bem como o aumento da excentricidade, sendo que as variações com a excentricidade ocorreram mais significativas para valores maiores que 0,25 . Este fato é explicado pelo autor devido ao maior efeito da rotação da coluna na região mais estreita do anular. O perfil de velocidade sofre maior influência da rotação da coluna nas áreas mais próximas da coluna, com dissipação do efeito à medida que a distância aumenta. Os autores concluíram que a rotação da coluna melhorou a limpeza do poço, especialmente com o aumento da excentricidade, e não somente com o fluxo axial.

No mesmo ano, Kelessidis [19] propôs um modelo ideal utilizando a geometria de cilindro concêntrico, no qual o valor da tensão de escoamento é estimado utilizando o método da seção áurea enquanto a consistência e o índice de comportamento do fluido são determinados através de uma regressão linear sobre os dados reométricos transformados. O autor menciona que o modelo Power-law, utilizado comumente como a primeira correção para fluido Newtoniano, pode resultar em erros significativos caso o fluido apresente tensão de escoamento. $\mathrm{O}$ modelo de Herschel-Bulkley é o que melhor descreve a reologia dos fluidos de perfuração, mas sua utilização não é frequente devido à complexidade da derivação dos três parâmetros do modelo. Os resultados numéricos foram comparados a resultados experimentais realizados com fluidos pseudoplásticos, demonstrando que o modelo de Herschel-Bulkley é apropriado. Nos casos onde se obtêm tensão de escoamento negativa através da regressão não linear, o método de Golden Section Search irá apresentar valores mais precisos e positivos para a tensão de escoamento. Foi identificado pelo autor que os melhores resultados são obtidos quando levados em consideração o perfil de velocidade e gradiente de pressão no ajuste dos índices, e não simplesmente uma análise estatística.

No mesmo ano, Pina e Carvalho [20] desenvolveram um modelo de fluxo tridimensional para estudar os efeitos da variação da excentricidade ao longo de um poço. A teoria da Lubrificação foi utilizada para simplificar as equações de 
conservação de quantidade de movimento para um fluido Newtoniano, resultando em um modelo bidimensional, de baixo custo computacional, descrevendo o perfil de pressão ao longo do poço. Os resultados mostraram o efeito da variação da excentricidade ao longo da coordenada axial no campo de velocidade e na perda de carga no espaço anular. Foi observada ocorrência de escoamento na direção azimutal mesmo na ausência de rotação do cilindro interno.

Ahmed e Miska [21], no ano de 2008, desenvolveram um experimento para analisar o comportamento do fluxo de um fluido Herschel-Bulkley em anular concêntrico e excêntrico, com rotação da coluna. Adicionalmente, um estudo analítico do fluxo helicoidal em anulares concêntricos foi conduzido. Ao comparar os resultados analíticos e experimentais de fluxo em anular concêntrico, observou-se que os dados medidos experimentalmente apresentaram uma maior perda de carga, principalmente a baixas velocidades. De uma maneira geral, o aumento da velocidade de rotação da coluna foi acompanhado de uma diminuição da perda de carga. Isto se deve ao fato da predominância do efeito pseudoplástico em anulares concêntricos e ligeiramente excêntricos. Em compensação, nos anulares com alta excentricidade observou-se de maneira geral um aumento da perda de carga com o aumento da velocidade da rotação da coluna devido à predominância do efeito de inércia, em altas vazões de fluxo. Para os casos de baixas vazões de fluxo o efeito pseudoplástico foi predominante, com redução da perda de carga. O modelo analítico apresentou dados precisos somente nos casos de anulares concêntricos.

Moroni et al [22], no ano de 2009, estudaram os efeitos da rotação da coluna de perfuração em anular excêntrico no perfil de velocidade e gradiente de pressão. O objetivo do estudo era aperfeiçoar os vários fatores durante uma operação de cimentação e otimizar as operações de limpeza de poço e substituição do cimento. Os resultados analíticos obtidos do modelo de Herschel-Bulkley foram comparados aos dados medidos de campo. Os resultados demonstraram que somente o efeito da velocidade não pode garantir que o fluido de espaçamento irá penetrar em ambas as regiões do anular, estreita e ampla. Entretanto, identificouse que as combinações do fluido de escoamento, com apropriada reologia e rotação da coluna propiciam um valor de tensão de cisalhamento maior que o 
valor de tensão de escoamento do fluido de perfuração a ser deslocado. Este estudo demonstra que a otimização da reologia do fluido, rotação da coluna e fluxo axial ajudam na remoção do fluido de perfuração em todo anular, melhorando a eficiência da limpeza do poço.

No mesmo ano, Alexandre e Carvalho [23] avaliaram o campo de velocidade de fluidos não Newtonianos em geometria anular excêntrica tridimensional a partir de um modelo que considerou os efeitos da curvatura da folga radial, utilizando a simplificação da teoria da Lubrificação. A simplificação resulta em uma equação diferencial para o campo de pressão, onde a grande vantagem da metodologia empregada é o pequeno custo computacional. Os resultados mostraram que para um dado gradiente de pressão, a vazão volumétrica do escoamento aumenta com o afastamento do cilindro interno em relação ao cilindro externo, e que a razão de raios praticamente não provoca alteração no produto $f$. Re para pequenas excentricidades. Através do método da Viscosidade Newtoniana Equivalente foi possível observar a distribuição da viscosidade efetiva do fluido ao longo do espaço anular, sendo observada uma área ao centro do domínio onde o fluido apresenta viscosidade efetiva elevada e outra zona na periferia de baixa viscosidade efetiva.

O principal objetivo dos trabalhos publicados na literatura é obter o campo de velocidade ou a perda de carga no espaço anular em função das variáveis e geometria do problema.

\section{3 \\ Proposta e Objetivo}

Modelos matemáticos precisos apresentados na literatura para descrever o escoamento de fluidos de perfuração são relativamente complexos e caros do ponto de vista computacional. Neste trabalho, pretende-se ampliar o estudo realizado por Alexandre e Carvalho [23], através do desenvolvimento de um modelo simplificado pela teoria da Lubrificação em coordenadas cilíndricas, incluindo o efeito da rotação da coluna de perfuração. 
Em razão do comportamento não Newtoniano dos fluidos de perfuração, é significativa a influência da rotação da coluna na perda de carga, em virtude da variação da viscosidade dos fluidos com a taxa de deformação imposta.

Para efeitos de simplificação do modelo matemático, a excentricidade será constante ao longo da coordenada axial. Entretanto vários casos com diferentes excentricidades, assim como diferentes velocidades de rotação da coluna de perfuração serão analisados a fim de se identificar o comportamento do perfil de velocidade do fluido e perda de carga do escoamento.

O modelo desenvolvido é validado através de comparações com resultados de estudos numéricos com formulação completa (e alto custo computacional) para fluido Power-law disponível na literatura a fim de verificar a precisão do modelo proposto e possibilitar o emprego desse modelo em trabalhos futuros na seleção de um fluido de perfuração que possibilite tanto uma melhoria operacional como uma redução de custo. 


\section{2 Modelo}

Neste capítulo apresentam-se as equações que descrevem o escoamento em um espaço anular com rotação do cilindro interno utilizadas no desenvolvimento do modelo proposto. A equação de Navier-Stokes em coordenadas cilíndricas foi simplificada utilizando-se a teoria da Lubrificação para escoamentos de fluidos viscosos em pequenos espaçamentos.

As equações de Conservação de Massa e Quantidade de Movimento e as equações constitutivas para os fluidos não Newtonianos foram aplicadas seguindo as hipóteses:

- Fluido incompressível;

- $\quad$ Fluido inelástico;

- $\quad$ Regime permanente;

- $\quad$ Escoamento laminar;

- Escoamento isotérmico.

\section{1 \\ Geometria}

Para a modelagem do problema de escoamento no espaço anular formado entre o revestimento e a parede do poço, optou-se por utilizar o sistema de coordenadas cilíndricas, onde (z) será a direção principal do escoamento, (r) será a direção radial e $(\theta)$ será a direção circunferencial do escoamento.

A origem do sistema de coordenadas em cada seção transversal será representada pelo centro do cilindro interno, onde sua excentricidade $(e)$ em relação ao cilindro externo será constante ao longo da coordenada axial (comprimento do poço). Essa excentricidade definirá a posição do cilindro externo em relação à origem do sistema de coordenadas. $\mathrm{O}$ raio dos cilindros interno e externo é constante, sendo respectivamente, $R_{i}$ e $R_{o}$. A Figura 8 ilustra a 
configuração do anular da geometria a ser estudada, onde a excentricidade e raios dos cilindros serão dados de entrada do problema.

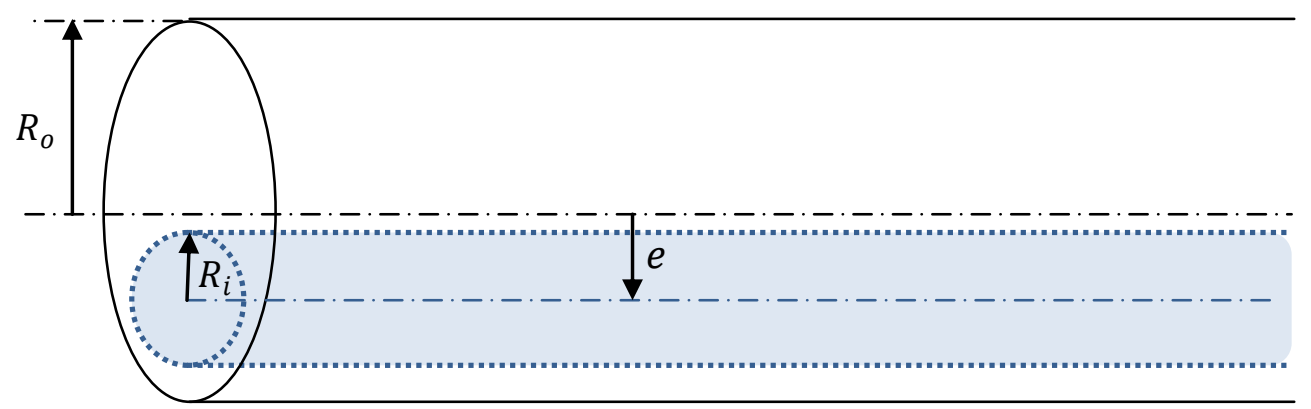

Figura 8 - Espaço anular com excentricidade constante

A Figura 9 apresenta a seção transversal da geometria a ser estudada, onde se pode identificar o triângulo formado pelas variáveis: excentricidade, raio externo $R_{o}$ e coordenada radial da parede do cilindro externo $R(\theta)$ em relação à origem do sistema de coordenadas.

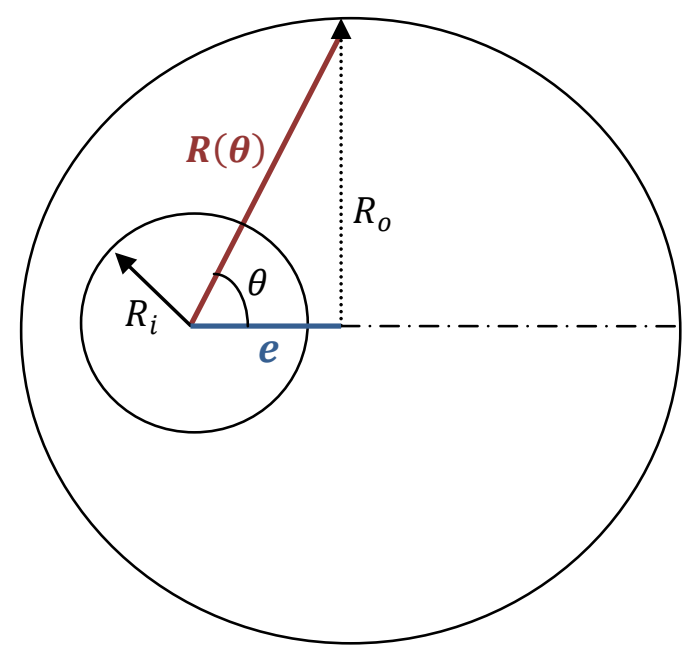

Figura 9 - Configuração da seção transversal

Assim, utilizando a lei dos cossenos, obtém-se a equação (2-1) que descreve a posição da parede do cilindro externo em função da coordenada $\theta$ do raio do cilindro externo e da excentricidade.

$$
R_{o}^{2}=R^{2}+e^{2}-2 e R \cos \theta
$$


Resolvendo a equação do segundo grau dada pela equação (2-1) obtém-se uma expressão para a coordenada radial da parede do cilindro externo $R(\theta)$ para a geometria do modelo proposto:

$$
R(\theta)=e \cos \theta+\sqrt{R_{o}^{2}-e^{2} \sin ^{2} \theta}
$$

\section{2}

\section{Escoamento não Newtoniano}

Um fluido é uma substância que se deforma continuamente sob a aplicação de uma tensão de cisalhamento (tangencial), não importa quão pequena ela seja. No caso dos fluidos não Newtonianos, a tensão de cisalhamento não é diretamente proporcional à taxa de deformação, desta forma a viscosidade do fluido varia com a taxa de cisalhamento.

A relação entre a viscosidade e a taxa de cisalhamento pode ser analisada graficamente através das curvas de viscosidade. A Figura 10 apresenta curvas de viscosidade para diferentes tipos de fluidos, em uma mesma condição de temperatura e pressão. Note-se que todas as curvas de viscosidade, exceto a curva A, referem-se a tipos de fluidos não Newtonianos.

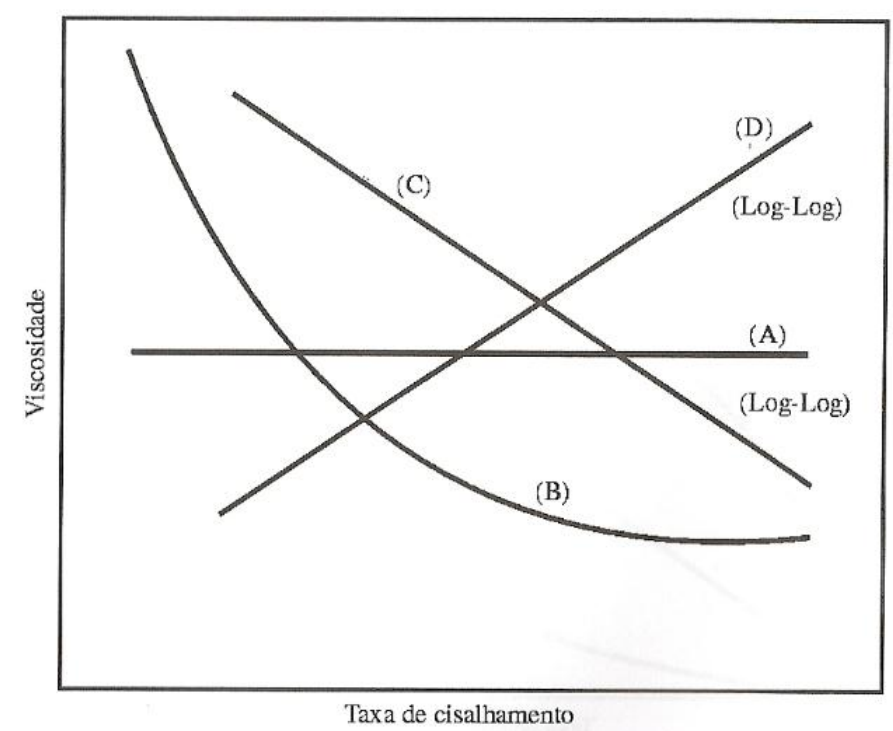

Figura 10 - Curva de Viscosidade de Fluido: (A) Newtoniano; (B) plástico ideal ou Binghamiano; (C) pseudoplástico; e (D) dilatante [24]. 
A caracterização dos fluidos ocorre de diferentes maneiras por diferentes autores. O American Petroleum Institute (API) considera fluido de perfuração qualquer fluido circulante capaz de tornar a operação de perfuração viável. Contudo, autores como Thomas et al [4] consideram os fluidos de perfuração como misturas complexas de sólidos, líquidos, produtos químicos e, por vezes, até de gases. Sendo que, do ponto de vista químico, eles podem assumir aspectos de suspensão, dispersão coloidal ou emulsão, dependendo do estado físico dos componentes. Do ponto de vista físico, os fluidos de perfuração assumem comportamento de fluidos não Newtonianos.

Para um fluido não Newtoniano, a tensão é escrita como:

$$
\tau=\mu_{a} \dot{\gamma}
$$

onde a viscosidade $\mu_{a}$ varia com a taxa de deformação.

Para melhor descrever o comportamento mecânico dos fluidos não Newtonianos, é necessário estabelecer a relação entre a tensão aplicada no fluido e a taxa de deformação em diferentes condições de escoamento. Esta relação é descrita pelas inúmeras equações constitutivas disponíveis na literatura. No presente trabalho optou-se pela utilização do modelo de Fluido Newtoniano Generalizado, o qual é o resultado de uma pequena modificação da equação constitutiva de um fluido Newtoniano, apresentado pela equação (2-7):

$$
\tau=\eta(\dot{\gamma}) \dot{\gamma}
$$

onde a viscosidade $\mu$ do fluido é substituída por uma função viscosidade $\eta(\dot{\gamma})$, que depende da intensidade da taxa de deformação imposta ao fluido.

A fim de descrever o comportamento do fluido de maneira mais próxima à realidade, experimentos foram realizados com os fluidos de interesse por diversos autores para determinar as funções viscosidade. A Tabela 1 apresenta algumas funções viscosidade resultantes destes experimentos, amplamente utilizadas na literatura. 
Tabela 1 - Funções Viscosidade e parâmetros reológicos de fluidos não Newtonianos

\begin{tabular}{|c|c|c|}
\hline Modelo & Função Viscosidade & Parâmetros \\
\hline \hline Newton & $\tau=\mu \gamma$ & viscosidade dinâmica absoluta \\
\hline Bingham & $\tau=\mu_{p} \gamma+\tau_{L}$ & viscosidade plástica e limite de \\
\hline Power-law & $\tau=\eta_{0} \gamma^{n}$ & escoamento \\
\hline Herschell-Buckley & $\tau=\eta_{0} \gamma^{n}+\tau_{0}$ & $\eta_{0}, n$ e $\tau_{0}$ \\
\hline Robertson-Stiff & $\tau=a\left(\gamma+\gamma_{0}\right)^{b}$ & a, b e $\gamma_{0}$ \\
\hline Casson & $\tau{ }^{1 / 2}=\left(\mu_{\infty} \gamma\right)^{1 / 2}+\tau_{0}{ }^{1 / 2}$ & $\mu_{\infty}$ e $\tau_{0}$ \\
\hline
\end{tabular}

O modelo computacional desenvolvido neste trabalho utilizou a função viscosidade descrita pelo modelo Power-law, a fim de comparar os resultados com um trabalho já existente na literatura.

A Figura 11 representa as curvas de fluxo para os fluidos que seguem o modelo Power-law, onde a viscosidade dos fluidos pseudoplásticos diminui com o aumento da taxa de cisalhamento, enquanto a viscosidade dos fluidos dilatantes aumenta com o aumento da taxa de cisalhamento.

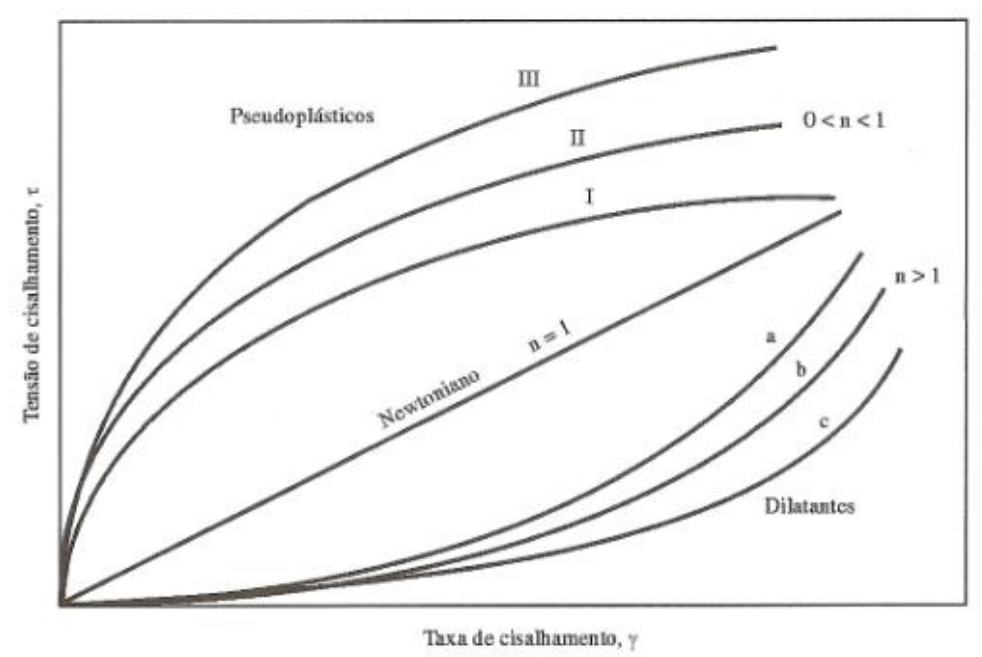

Figura 11 - Curva de Fluxo do fluido de Power-law ou de Potência: I, II, III pseudoplásticos com $0<\mathrm{n}<1 ; \mathrm{a}, \mathrm{b}, \mathrm{c}$, dilatantes com $\mathrm{n}>1$ [24]. 
O modelo Power-law, ou lei de potência, é usualmente utilizado para determinar o comportamento viscoso dos fluidos devido à sua simplicidade matemática. Entretanto, para taxas de cisalhamento ou tensões de cisalhamento muito altas ou muito baixas, o valor da viscosidade calculada com este modelo pode apresentar valores irreais.

\section{3}

\section{Teoria da Lubrificação}

O modelo matemático de escoamento de fluidos não Newtonianos consiste habitualmente das equações de conservação de massa e quantidade de movimento, acrescidas da equação constitutiva que estabeleça viscosidade do fluido em função da cinemática do escoamento. A solução destas equações de forma a descrever um escoamento não Newtoniano tridimensional é complexa e computacionalmente cara.

O conceito básico da teoria da Lubrificação é simplificar as equações que governam o problema, tornando-as bidimensionais sem perder a precisão do modelo. Este método de simplificação consiste em analisar a ordem de grandeza de cada termo, desprezando os termos que sejam bem menores que os demais. Com isso, os termos da equação de Navier-Stokes menores que os demais são desprezados, e um sistema de equações mais simples é obtido.

As equações de Navier-Stokes para o escoamento interno de um fluido viscoso incompressível, com massa específica e viscosidade constantes, em regime permanente e coordenadas cilíndricas são apresentadas abaixo:

Componente axial, $z$ :

$$
\rho\left(\frac{\partial u}{\partial t}+v \frac{\partial u}{\partial r}+\frac{w}{r} \frac{\partial u}{\partial \theta}+u \frac{\partial u}{\partial z}\right)=\rho g_{z}-\frac{\partial p}{\partial z}+\mu\left\{\frac{1}{r} \frac{\partial}{\partial r}\left(r \frac{\partial u}{\partial r}\right)+\frac{1}{r^{2}} \frac{\partial^{2} u}{\partial \theta^{2}}+\frac{\partial^{2} u}{\partial z^{2}}\right\}
$$


Componente radial, $r$ :

$$
\begin{aligned}
\rho\left(\frac{\partial v}{\partial t}+v \frac{\partial v}{\partial r}+\right. & \left.\frac{w}{r} \frac{\partial v}{\partial \theta}-\frac{w^{2}}{r}+u \frac{\partial v}{\partial z}\right) \\
& =\rho g_{r}-\frac{\partial p}{\partial r}+\mu\left\{\frac{\partial}{\partial r}\left(\frac{1}{r} \frac{\partial}{\partial r}[r v]+\frac{1}{r^{2}} \frac{\partial^{2} v}{\partial \theta^{2}}-\frac{2}{r^{2}} \frac{\partial w}{\partial \theta}+\frac{\partial^{2} v}{\partial z^{2}}\right)\right\}
\end{aligned}
$$

Componente azimutal, $\theta$ :

$$
\begin{aligned}
\rho\left(\frac{\partial w}{\partial t}+v \frac{\partial w}{\partial r}+\right. & \left.\frac{w}{r} \frac{\partial w}{\partial \theta}+\frac{v w}{r}+u \frac{\partial w}{\partial z}\right) \\
& =\rho g_{\theta}-\frac{1}{r} \frac{\partial p}{\partial \theta}+\mu\left\{\frac{\partial}{\partial r}\left(\frac{1}{r} \frac{\partial}{\partial r}[r w]\right)+\frac{1}{r^{2}} \frac{\partial^{2} w}{\partial \theta^{2}}+\frac{2}{r^{2}} \frac{\partial v}{\partial \theta}+\frac{\partial^{2} w}{\partial z^{2}}\right\}
\end{aligned}
$$

onde $u, v$ e $w$ são, respectivamente, as componentes axial, radial e azimutal da velocidade.

No estudo em questão é necessário levar em consideração as operações de perfuração a fim de determinar quais parâmetros deverão ser simplificados pela teoria da Lubrificação.

No caso de um poço de perfuração, o comprimento do poço é muito maior do que os raios interno $\left(R_{i}\right)$ e externo $\left(R_{o}\right)$, que por sua vez são bem maiores que a distância entre a parede dos cilindros $\left(R_{o}-R_{i}\right)$, ou seja:

$$
R_{o}, R_{i}<L \quad \text { e } \quad R_{o}-R_{i} \ll R \ll L
$$

Consequentemente, o escoamento ocorre predominantemente na direção axial, sendo a velocidade na direção radial muito menor que as outras duas componentes, ou seja:

$$
v \ll u, w
$$

Essas hipóteses levam às seguintes conclusões:

$$
\begin{gathered}
\frac{\partial u}{\partial r} \gg \frac{\partial u}{\partial z}, \frac{\partial u}{\partial \theta} \\
\frac{\partial^{2} u}{\partial r^{2}} \gg \frac{\partial^{2} u}{\partial z^{2}}, \frac{\partial^{2} u}{\partial \theta^{2}}
\end{gathered}
$$




$$
\begin{gathered}
\frac{\partial w}{\partial r} \gg \frac{\partial w}{\partial z}, \frac{\partial w}{\partial \theta} \\
\frac{\partial^{2} w}{\partial r^{2}} \gg \frac{\partial^{2} w}{\partial z^{2}}, \frac{\partial^{2} w}{\partial \theta^{2}}
\end{gathered}
$$

Outra hipótese a ser considerada é o efeito da força centrípeta ao longo do escoamento no anular. Como a magnitude desta força é consideravelmente inferior ao nível de pressão existente no poço (devido à coluna hidrostática), pode-se desprezá-la. Sendo assim:

$$
\frac{w^{2}}{r} \approx 0
$$

Para a solução do presente problema, considerou-se regime permanente e desconsideraram-se os efeitos da gravidade a fim de simplificar o modelo, ou seja:

$$
\begin{gathered}
\frac{\partial v}{\partial t}=\frac{\partial w}{\partial t}=\frac{\partial u}{\partial t}=0 \\
g_{r}, g_{z}, g_{\theta} \approx 0
\end{gathered}
$$

Desta forma, considerando as hipóteses descritas acima, as equações de Navier-Stokes podem ser simplificadas, sendo representadas por:

Componente axial, z:

$$
-\frac{\partial p}{\partial z}+\mu\left\{\frac{1}{r} \frac{\partial}{\partial r}\left(r \frac{\partial u}{\partial r}\right)\right\}=0
$$

Componente radial, $\mathrm{r}$ :

$$
-\frac{\partial p}{\partial r}=0
$$

Componente azimutal, $\theta$ :

$$
-\frac{1}{r} \frac{\partial p}{\partial \theta}+\mu\left\{\frac{\partial}{\partial r}\left(\frac{1}{r} \frac{\partial}{\partial r}[r w]\right)\right\}=0
$$

Observando a equação (2-4) é possível concluir que o campo de pressão não varia com a coordenada radial, sendo uma função apenas das coordenadas azimutal e axial, ou seja, $p=p(\theta, z)$. Esta conclusão é bastante razoável do ponto de vista da perfuração de um poço, uma vez que a ordem de grandeza da folga 
radial é bem menor comparada à ordem de grandeza do comprimento do poço. Desta forma, a variação de pressão ao longo da coordenada radial é desprezível.

As componentes axial e azimutal da equação de Navier-Stokes obtidas pela simplificação da teoria da Lubrificação, representadas pelas equações (2-3) e (25), possuem os gradientes de pressão não dependentes da coordenada radial. Considerando-se o escoamento de um fluido Newtoniano, e utilizando condições de contorno apropriadas podem-se integrar analiticamente as equações das componentes axial e azimutal obtendo-se os perfis de velocidades.

A hipótese de fluido Newtoniano é realizada a fim de possibilitar a obtenção do campo de velocidades de maneira analítica. As equações para fluido não Newtoniano necessitam da aplicação de um método numérico para obtenção do perfil de velocidade.

As condições de contorno utilizadas para a componente axial da velocidade na integração foram:

$$
\begin{aligned}
& u\left(R_{i}\right)=0 \\
& u(R(\theta))=0
\end{aligned}
$$

Desta forma, o perfil da velocidade axial obtida pela integração é representado pela equação (2-6) abaixo:

$$
u(r, \theta)=\frac{R_{i}^{2}}{4 \mu}\left(-\frac{\partial P}{\partial z}\right)\left[1-\left(\frac{r}{R_{i}}\right)^{2}+\left(\left(\frac{R}{R_{i}}\right)^{2}-1\right) \frac{\ln \left(r / R_{i}\right)}{\ln \left(R / R_{i}\right)}\right]
$$

onde se assumiu a hipótese de gradiente de pressão ao longo da componente axial $(\partial P / \partial z)$ conhecido a fim de simplificar o modelo proposto.

As condições de contorno utilizadas para a componente azimutal da velocidade na integração foram:

$$
\begin{aligned}
& w\left(R_{i}\right)=\Omega_{i} R_{i} \\
& w(R(\theta))=0
\end{aligned}
$$


onde $\Omega$ representa a rotação do cilindro interno.

Desta forma, o perfil da velocidade azimutal obtida pela integração é representado pela equação (2-7) abaixo:

$$
\begin{aligned}
w(r, \theta)= & \frac{\Omega_{i} R_{i}^{2}}{\left(R^{2}-R_{i}^{2}\right)}\left(\frac{R^{2}}{r}-r\right) \\
& \quad+\frac{R_{i}^{2}}{2 \mu} \frac{\partial P}{\partial \theta}\left[\frac{r}{R_{i}^{2}} \ln (r / R)+\frac{1}{\left(R^{2}-R_{i}^{2}\right)}\left(\frac{R^{2}}{r}-r\right) \ln \left(R / R_{i}\right)\right]
\end{aligned}
$$

onde o gradiente de pressão ao longo da componente azimutal $(\partial P / \partial \theta)$ foi considerado desprezível, simplificando a solução do modelo proposto.

Cada componente da velocidade é função das coordenadas radial e azimutal, onde a dependência da coordenada azimutal é implicitamente definida através da coordenada radial da parede do cilindro externo $R=R(\theta)$, representada pela equação (2-2).

A vazão volumétrica do fluido de perfuração possui importante relevância na eficiência da remoção dos cascalhos no interior do poço, onde uma estimativa próxima da realidade propiciará a escolha do fluido mais adequado à situação de interesse. A vazão volumétrica através de uma seção de uma superfície de controle é representada pela equação (2-8):

$$
Q=A \cdot \bar{U}
$$

onde $A$ é a área da seção transversal do espaço anular, e $\bar{U}$ é a velocidade média do escoamento na direção axial.

Para o escoamento em espaço anular, a equação (2-8) é representada por:

$$
Q=\int_{0}^{2 \pi} \int_{R_{i}}^{R} u(r, \theta) r d r d \theta=\frac{1}{\pi\left(R^{2}-R_{i}^{2}\right)} \int_{0}^{2 \pi} F(\theta) d \theta
$$

onde $F(\theta)$ é obtida através da integração do perfil da velocidade axial na componente radial, representada pela equação (2-10). 


$$
\begin{aligned}
F(\theta)=\frac{R_{i}^{2}}{4 \mu}\left(-\frac{\partial P}{\partial z}\right)\left\{\frac{\left(R^{2}-R_{i}^{2}\right)}{2}-\frac{\left(R^{4}-R_{i}^{4}\right)}{4 R_{i}^{2}}\right. \\
\left.+\frac{\left(R / R_{i}\right)^{2}-1}{4 \ln \left(R / R_{i}\right)}\left[R^{2}\left(2 \ln \left(R / R_{i}\right)-1\right)+R_{i}^{2}\right]\right\}
\end{aligned}
$$

A hipótese de fluido Newtoniano possibilitou a obtenção da vazão do escoamento em função de um gradiente de pressão imposto. Entretanto o modelo proposto tem por objetivo estudar o escoamento de fluidos não Newtonianos. Para isso, o método da Viscosidade Newtoniana Equivalente, descrito a seguir, será utilizado.

\section{4 \\ Método da Viscosidade Newtoniana Equivalente}

O modelo da teoria de Lubrificação apresentado anteriormente foi desenvolvido para fluido Newtoniano, o que possibilitou o cálculo analítico do perfil de velocidade e vazão. O comportamento não Newtoniano é incluído no modelo utilizando o conceito de Viscosidade Newtoniana Equivalente, onde o valor da viscosidade em cada ponto do domínio 2D (plano $\theta-z$ ) é calculado como a viscosidade de um fluido Newtoniano equivalente que possui a mesma relação vazão-gradiente de pressão do escoamento não Newtoniano.

Em 1975, Broyer [25] apresentou o modelo de Viscosidade Newtoniana Equivalente em coordenadas cartesianas como uma solução à imprecisão no cálculo da vazão de escoamento não Newtoniano entre duas placas paralelas.

A expressão de Viscosidade Newtoniana Equivalente foi obtida através da comparação das vazões volumétricas para fluido Newtoniano e não Newtoniano, descritas abaixo nas equações (2-11) e (2-12), respectivamente.

$$
q=\frac{2}{3} \frac{h^{2} \tau_{w}}{\mu}
$$




$$
q=-\frac{2 h^{2}}{\tau_{w}^{2}} \int_{0}^{\tau_{w}} \tau \dot{\gamma} d \tau
$$

onde $h$ é a distância do centro do escoamento até a parede da placa, $\tau_{w}$ é a tensão de cisalhamento na parede, $\mu$ é a viscosidade considerando fluido Newtoniano, e $\dot{\gamma}$ é a taxa de cisalhamento para um fluido não Newtoniano.

Igualando as equações (2-11) e (2-12) resulta em uma expressão para Viscosidade Newtoniana Equivalente para um determinado valor de tensão cisalhante na parede $\tau_{w}$ (gradiente de pressão $\Delta P / L$ ). O modelo constitutivo é incluído na formulação através da função que descreve $\eta(\tau)$.

$$
\bar{\mu}=\frac{\tau_{w}^{3}}{3 \int_{0}^{\tau_{w}} \frac{\tau^{2}}{\eta(\tau)}}
$$

O Método da Viscosidade Newtoniana Equivalente utilizado no modelo proposto será em coordenadas cilíndricas, sendo assim uma modificação do método original apresentado por Broyer [25]. A utilização de coordenadas cilíndricas melhora a precisão do modelo quando a razão de raios do espaço anular se afasta da unidade, e é obtida de maneira similar ao apresentado acima para coordenadas cartesianas.

Sendo assim, a expressão para a Viscosidade Newtoniana Equivalente é então obtida para o espaço anular considerando um fluido com qualquer comportamento reológico, representada na equação (2-14) abaixo.

$$
\bar{\mu}=\frac{R_{o}^{2}\left[\frac{1-\left(\frac{R_{i}}{R_{o}}\right)^{4}}{1-\left(\frac{R_{i}}{R_{o}}\right)^{2}}-\frac{1-\left(\frac{R_{i}}{R_{o}}\right)^{2}}{\ln \left(\frac{R_{o}}{R_{i}}\right)}\right]}{8 \int_{R_{i}}^{R_{o}} \frac{\tau}{\eta(\tau)} r^{2} d r}\left[1-\left(\frac{R_{i}}{R_{o}}\right)^{2}\right]\left(-\frac{d P}{d z}\right)
$$


Onde $\eta(\tau)$ é a função viscosidade para um fluido não Newtoniano. A função viscosidade do modelo Power-law foi a selecionada dentre algumas funções viscosidade apresentadas na Tabela 1 para o modelo proposto neste trabalho.

A função viscosidade utilizada em função da tensão de cisalhamento de um fluido Power-law é apresentada a seguir:

$$
\eta(\tau)=\eta_{0}^{\frac{1}{n}}|\tau|^{\frac{n-1}{n}}
$$

onde $\eta_{0}$ é chamado de índice de consistência do fluido e $n$ é chamado de índice de comportamento do fluido, sendo determinados a partir de experimentos realizados com o fluido de interesse.

No modelo computacional desenvolvido neste trabalho utilizou-se $\eta_{0}=1$ a fim de possibilitar comparação com os resultados obtidos em um trabalho já existente na literatura.

O cálculo da viscosidade é feito a partir do estado de tensões aplicado ao fluido, do modelo reológico adotado e da geometria na região avaliada do domínio. A Figura 12 ilustra a configuração da geometria a ser estudada, onde o cilindro externo representa a formação e o cilindro interno a coluna de perfuração com rotação.

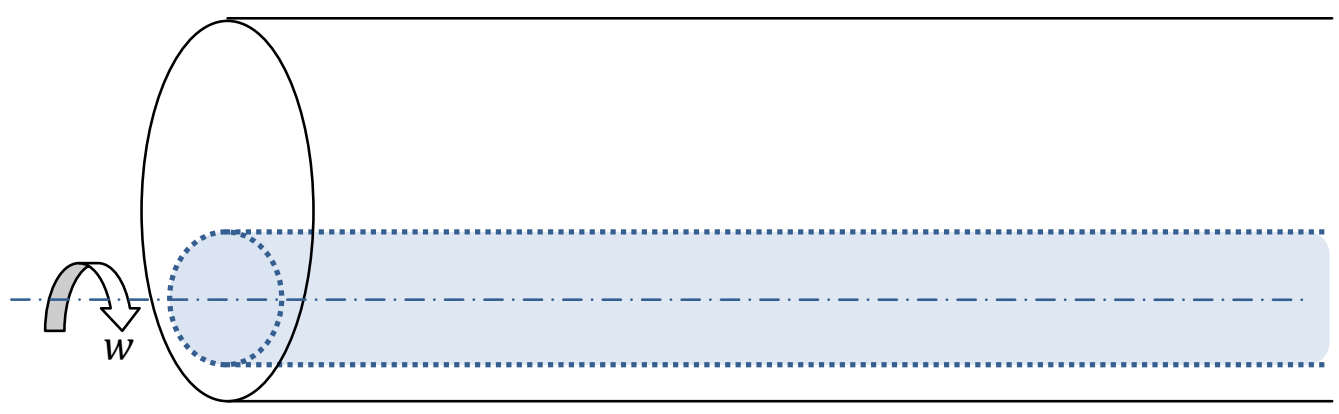

Figura 12 - Rotação do cilindro interno em espaço anular excêntrico.

As tensões cisalhantes presentes no escoamento no espaço anular em coordenadas cilíndricas são apresentadas abaixo: 
Componente radial, $r$ :

$$
\tau_{z r}=\mu\left(\frac{\partial v}{\partial z}+\frac{\partial u}{\partial r}\right)
$$

Componente azimutal, $\theta$ :

$$
\tau_{r \theta}=\mu\left[r \frac{\partial}{\partial r}\left(\frac{w}{r}\right)+\frac{1}{r} \frac{\partial v}{\partial \theta}\right]
$$

A solução desse problema é não linear, visto que o estado de tensões utilizado no cálculo da viscosidade é função da própria viscosidade do fluido em cada ponto da coordenada radial.

Aplicando-se a simplificação da teoria da Lubrificação descrita anteriormente, pode-se desprezar a componente da velocidade na direção radial devido o escoamento ocorrer predominantemente na direção axial. Sendo assim, as componentes de tensão de cisalhamento radial e azimutal podem ser simplificadas, sendo representadas por:

Componente radial, $r$ :

$$
\tau_{z r}=\mu \frac{\partial u}{\partial r}
$$

Componente azimutal, $\theta$ :

$$
\tau_{r \theta}=\mu\left[r \frac{\partial}{\partial r}\left(\frac{w}{r}\right)\right]
$$

A equação (2-3) da quantidade de movimento ao longo da coordenada axial pode ser representada em função da tensão de cisalhamento da componente radial (2-18), conforme equação (2-20) abaixo:

$$
-\frac{\partial p}{\partial z}+\frac{1}{r} \frac{\partial}{\partial r}\left(r \tau_{z r}\right)=0
$$

A tensão cisalhante no espaço anular para um fluido qualquer pode ser obtida através da integração da equação (2-20) ao longo da coordenada radial e da utilização de uma condição de contorno apropriada, logo:

$$
\tau_{r z}=\left(-\frac{d P}{d z}\right) \frac{R}{2}\left[\frac{r}{R}-\beta^{2} \frac{R}{r}\right]
$$


onde no ponto $r=\beta R_{o}$ a velocidade é máxima e a tensão de cisalhamento é nula. $\beta$ depende do comportamento reológico do fluido e da relação de raios do espaço anular $(k)$. Valores de $\beta$ para diferentes valores de $k$ e $n$ são apresentados na Tabela 2.

$$
\tau_{r z}(\beta r)=0
$$

Tabela 2 - Valores de $\beta(k, n)$

\begin{tabular}{|c|c|c|c|c|c|c|c|c|c|}
\hline & \multicolumn{9}{|c|}{$k\left(\boldsymbol{R}_{\boldsymbol{i}} / \boldsymbol{R}\right)$} \\
\hline $\boldsymbol{n}$ & $\mathbf{0 . 1 0}$ & $\mathbf{0 . 2 0}$ & $\mathbf{0 . 3 0}$ & $\mathbf{0 . 4 0}$ & $\mathbf{0 . 5 0}$ & $\mathbf{0 . 6 0}$ & $\mathbf{0 . 7 0}$ & $\mathbf{0 . 8 0}$ & $\mathbf{0 . 9 0}$ \\
\hline $\mathbf{0 . 1 0}$ & 0.3442 & 0.4687 & 0.5632 & 0.6431 & 0.7140 & 0.7788 & 0.8389 & 0.8954 & 0.9489 \\
\hline $\mathbf{0 . 2 0}$ & 0.3682 & 0.4856 & 0.5749 & 0.6509 & 0.7191 & 0.7818 & 0.8404 & 0.8960 & 0.9491 \\
\hline $\mathbf{0 . 3 0}$ & 0.3884 & 0.4991 & 0.5840 & 0.6570 & 0.7229 & 0.7840 & 0.8416 & 0.8965 & 0.9492 \\
\hline $\mathbf{0 . 4 0}$ & 0.4052 & 0.5100 & 0.5912 & 0.6617 & 0.7259 & 0.7858 & 0.8426 & 0.8969 & 0.9493 \\
\hline $\mathbf{0 . 5 0}$ & 0.4193 & 0.5189 & 0.5970 & 0.6655 & 0.7283 & 0.7872 & 0.8433 & 0.8972 & 0.9493 \\
\hline $\mathbf{0 . 6 0}$ & 0.4312 & 0.5262 & 0.6018 & 0.6686 & 0.7303 & 0.7884 & 0.8439 & 0.8975 & 0.9494 \\
\hline $\mathbf{0 . 7 0}$ & 0.4412 & 0.5324 & 0.6059 & 0.6713 & 0.7319 & 0.7893 & 0.8444 & 0.8977 & 0.9495 \\
\hline $\mathbf{0 . 8 0}$ & 0.4498 & 0.5377 & 0.6093 & 0.6735 & 0.7333 & 0.7902 & 0.8449 & 0.8979 & 0.9495 \\
\hline $\mathbf{0 . 9 0}$ & 0.4572 & 0.5422 & 0.6122 & 0.6754 & 0.7345 & 0.7909 & 0.8452 & 0.8980 & 0.9495 \\
\hline $\mathbf{1 . 0 0}$ & 0.4637 & 0.5461 & 0.6147 & 0.6770 & 0.7355 & 0.7915 & 0.8455 & 0.8981 & 0.9496 \\
\hline
\end{tabular}

A avaliação da influência da rotação do cilindro interno no escoamento é possibilitada através da componente azimutal da tensão de cisalhamento, representada pela equação (2-19). Para o cálculo da tensão de cisalhamento $\tau_{\theta r}$, vamos considerar apenas a velocidade azimutal relacionada com a rotação da coluna;

$$
w=\frac{\Omega_{i} R_{i}^{2}}{R^{2}-R_{i}^{2}}\left[\frac{R^{2}}{r}-r\right]
$$

onde $w$ é a velocidade azimutal e as condições de contorno utilizadas no cálculo deste perfil foram:

$$
w\left(R_{i}\right)=\Omega_{i} R_{i}
$$




$$
w(R(\theta))=0
$$

onde $\Omega$ representa a rotação do cilindro interno.

Desta forma, a tensão de cisalhamento na coordenada azimutal é:

$$
\tau_{r \theta}=-2 \mu \frac{\Omega_{i} R_{i}^{2} R^{2}}{R^{2}-R_{i}^{2}} \frac{1}{r^{2}}
$$

onde a viscosidade $\mu$ do fluido é substituída por uma função viscosidade $\eta(\dot{\gamma})$, que depende da intensidade da taxa de deformação imposta ao fluido não Newtoniano.

A tensão cisalhante total é calculada pela soma de sua componentes:

$$
\tau=\sqrt{\tau_{r z}^{2}+\tau_{r \theta}^{2}}
$$

Como o estado de tensões utilizado no cálculo da viscosidade é função da própria viscosidade do fluido, faz-se necessária a utilização de um processo iterativo para a obtenção da viscosidade em cada ponto do domínio, que será descrito a seguir.

\section{5 \\ Solução do Modelo}

O modelo proposto foi desenvolvido em MATLAB e considera um escoamento desenvolvido em coordenadas cilíndricas, onde o comprimento do poço é muito maior do que os raios interno e externo, resultando em uma geometria bidimensional no plano $r-\theta$. Desta forma, adotou-se uma malha bidimensional retangular com $N R$ nós na direção radial e $N \theta$ nós na direção azimutal. A Figura 13 apresenta a geometria e sistema de coordenadas adotado na solução do problema.

Durante a fase de validação do modelo proposto duas diferentes malhas foram estudadas a fim de avaliar o erro numérico da solução e o número de nós a ser utilizado nas integrações numéricas da viscosidade e vazão volumétrica. Como 
ambas as malhas apresentaram os mesmos resultados, optou-se por utilizar no modelo proposto a malha com menor número de nós, consequentemente com menor custo computacional. As malhas analisadas são identificadas abaixo.

Malha 01: $N R=20$ e $N \theta=41$

Malha $02: N R=80$ e $N \theta=101$

onde $N R$ e $N \theta$ são o número de nós na direção radial e azimutal, respectivamente.
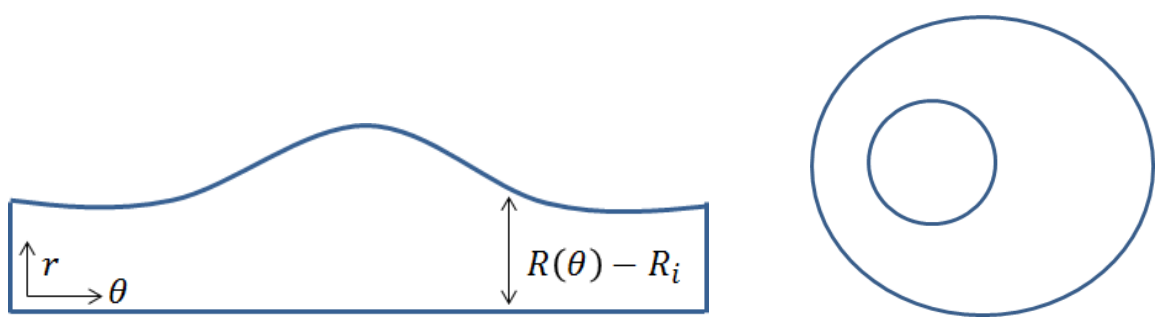

Figura 13 - Rotação do cilindro interno em espaço anular excêntrico.

\subsection{1 \\ Integração Numérica}

O método da Viscosidade Newtoniana Equivalente possibilitou a solução da vazão volumétrica do escoamento em espaço anular de um fluido não Newtoniano. Entretanto, as equações de vazão (2-9) e viscosidade (2-14) obtidas não podem ser resolvidas analiticamente devido à presença de integrais.

Com isso, para que as integrais das equações acima mencionadas possam ser calculadas é necessário que se utilize a aproximação da regra do trapézio. Este método consiste em aproximar o valor de uma função contínua $f(x)$ em determinado intervalo por uma função de primeira ordem. Isto é, a regra do trapézio consiste em aproximar uma função por uma reta qualquer, onde a solução da integral desejada é aproximadamente a área do trapézio formada pela reta, ilustrada pela Figura 14, e descrita numericamente pela equação (2-24):

$$
\int_{a}^{b} f(x) d x \cong \frac{\Delta x}{2}[f(a)+f(b)]
$$


onde $\Delta x$ é a largura do trapézio $(b-a)$, e $[f(a)+f(b)] / 2$ é a altura média do trapézio.

Para a aplicação da regra do trapézio no modelo proposto é necessário que seja definido um número de intervalos na faixa de integração, possibilitando assim a solução da integral em cada ponto do intervalo definido.

A solução da integral contida na equação de viscosidade é expressa abaixo, onde a faixa de integração é definida na coordenada radial.

$$
I_{\mu}=\int_{R_{i}}^{R_{O}} \frac{\tau}{\eta(\tau)} r^{2} d r=\int_{R_{i}}^{R_{O}} f(r) d r=\sum_{i=1}^{N R-1} \frac{\left[f\left(r_{i}\right)+f\left(r_{i+1}\right)\right]}{2} D r
$$

onde $N R$ é o número de nós na direção radial e $D r$ é a distância entre os nós na coordenada radial.

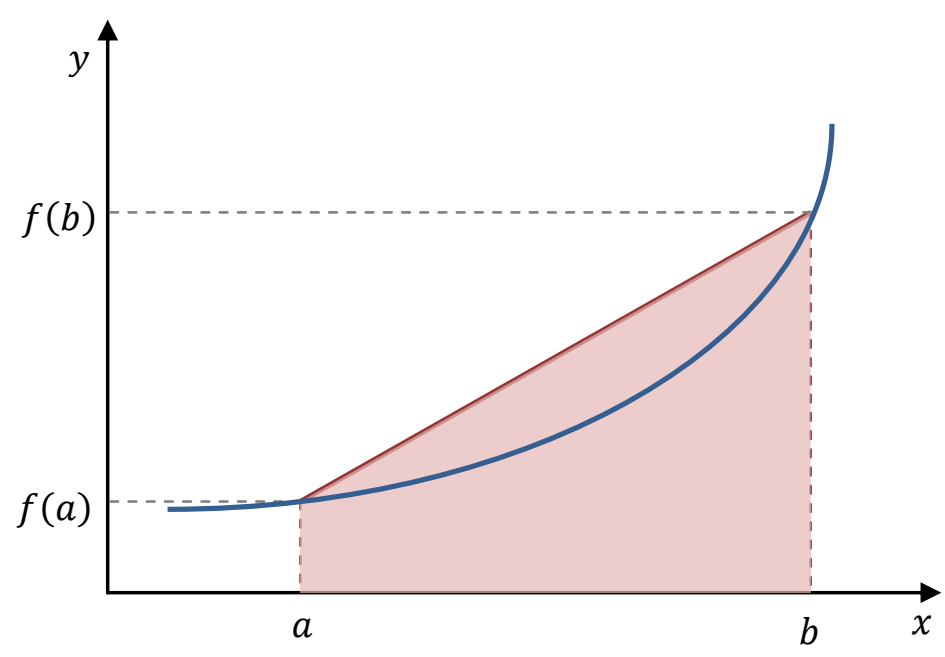

Figura 14 - Ilustração gráfica da regra do trapézio.

No caso do cálculo da vazão, a regra dos trapézios será aplicada na equação (2-9), e a faixa de integração será na coordenada azimutal.

$$
I_{Q}=\int_{0}^{2 \pi} F(\theta) d \theta=\sum_{1}^{N \theta-1} \frac{\left[F\left(\theta_{(i t-1)}\right)+F\left(\theta_{(i t)}\right)\right]}{2} D \theta
$$


onde $N \theta$ é o número de nós na direção azimutal e $D \theta$ é a distância entre os nós na coordenada azimutal.

\subsection{2 \\ Processo Iterativo}

Para que seja possível o cálculo da vazão volumétrica no escoamento não Newtoniano através de espaço anular com rotação da coluna, é necessário que se conheça a viscosidade Newtoniana equivalente em cada ponto do domínio.

Como o modelo proposto estuda o escoamento em espaço anular excêntrico com rotação do cilindro interno é necessário que a viscosidade seja função da tensão cisalhante radial e azimutal. Entretanto a componente azimutal é função da própria viscosidade, resultando em uma solução não linear. Desta forma, a utilização de um processo iterativo é requerida até que se consiga a convergência para um único valor de viscosidade. Cada passo do processo iterativo será descrito com detalhes a seguir.

O primeiro passo do processo iterativo é assumir vazão volumétrica nula, e que a viscosidade inicial será a de um fluido Newtoniano, igual ao valor do índice de consistência do modelo Power-law. Com isso, faz-se possível a solução das equações de tensão de cisalhamento nas componentes azimutal e radial. A partir da nova viscosidade calculada pode-se obter o valor de vazão volumétrica considerando o comportamento do fluido não Newtoniano.

O novo valor de vazão volumétrica será comparado com o valor assumido inicialmente, sendo que a convergência do processo é alcançada quando o valor do erro for menor ou igual à tolerância inicialmente definida. No modelo proposto definiu-se uma tolerância de 0.01 e o erro é calculado de acordo com a equação (2-27) abaixo:

$$
\text { Erro }=\left\|Q-Q_{\text {antes }}\right\|
$$

onde $Q$ representa a atual solução da vazão volumétrica e $Q_{\text {antes }}$ representa a solução obtida na interação anterior. 
O processo de cálculo de viscosidade e vazão volumétrica é repetido até que se alcance a convergência do modelo. O processo iterativo descrito acima é representado pela Figura 15.

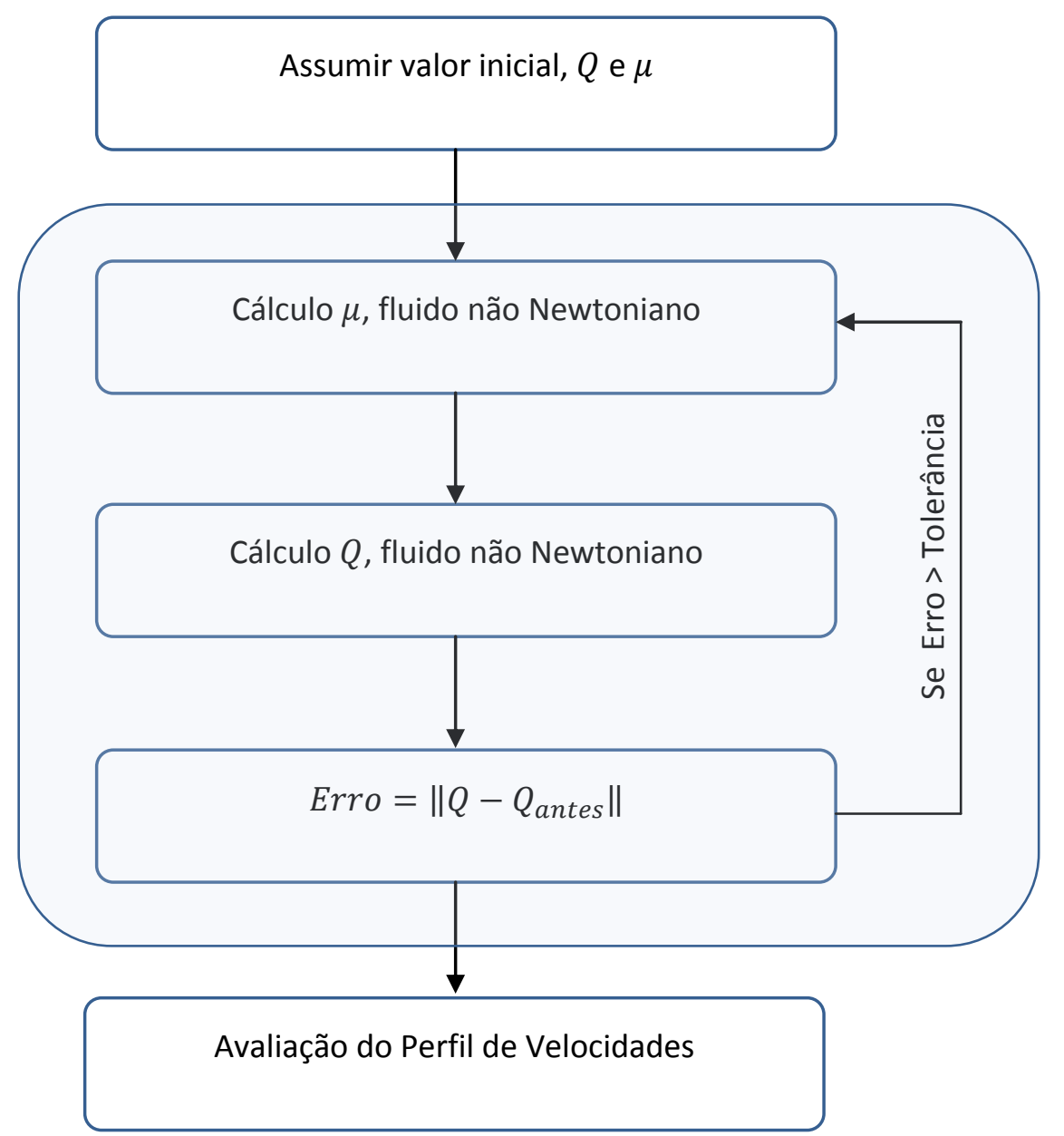

Figura 15 - Ilustração do processo iterativo do modelo proposto.

Ao final do processo iterativo o sistema de equações algébricas convergirá para a solução do problema, possibilitando a análise do comportamento reológico do fluido não Newtoniano através dos valores de viscosidade em cada ponto do domínio. A vazão volumétrica e perfil de velocidades possibilitarão a análise do escoamento do fluido não Newtoniano no espaço anular e rotação do cilindro interno. Essas informações serão de grande valia na escolha do fluido de perfuração a fim de se obter melhor eficiência durante a perfuração de um poço. 


\section{3 \\ Resultados}

O presente capítulo está dividido em três partes distintas, sendo a primeira a apresentação dos parâmetros adimensionais relevantes para a solução do modelo proposto, seguida pela validação do modelo, e finalizando com a análise dos resultados obtidos pelo modelo proposto.

A validação do modelo proposto foi realizada através da comparação dos resultados obtidos com equações disponíveis na literatura para situações limites ou estudos desenvolvidos por outros autores, para os casos mais complexos.

Ao fim deste capítulo, espera-se definir a faixa de aplicação do modelo proposto de modo a manter a precisão dos resultados em um modelo simplificado com menor custo computacional.

\section{1}

\section{Parâmetros Adimensionais}

O problema descrito é definido pelos seguintes parâmetros adimensionais:

- $\quad$ Razão de raios do anular $(k)$ :

$$
k=\frac{R_{i}}{R_{o}}
$$

- $\quad$ Excentricidade adimensional $(\varepsilon)$ :

$$
\varepsilon=\frac{e_{c}}{\left(R_{o}-R_{i}\right)}
$$

onde $e_{c}$ representa a excentricidade característica em questão. 
- $\quad$ Fator de atrito (f):

$$
f=\frac{2 \tau_{o}}{\left(\rho \bar{U}^{2}\right)}
$$

onde $\tau_{o}$ representa a tensão cisalhante nas paredes, $\rho$ a densidade do fluido e $\bar{U}$ a velocidade média do escoamento na direção axial.

Os parâmetros adimensionais número de Reynolds $\left(R e_{o}\right)$ e número de Taylor $\left(T a_{o}\right)$ foram calculados neste estudo considerando-se o modelo Power-law para análise do comportamento reológico dos fluidos não Newtonianos.

- Número de Reynolds $\left(\mathrm{Re}_{\mathrm{o}}\right)$ :

$$
R e_{o}=\frac{\rho \bar{U}^{(2-n)} D_{h}^{n}}{\eta_{0}}
$$

onde $R e_{o}$ representa o Número de Reynolds original sem rotação do cilindro interno $(w=0), D_{h}$ o diâmetro hidráulico na seção circular do escoamento, $n$ o índice de comportamento do modelo Power-law e $\eta_{0}$ o índice de consistência.

No modelo proposto utilizou-se $R e=100$ a fim de possibilitar comparação com os resultados obtidos em trabalhos disponíveis na literatura.

- Número de Taylor $\left(\mathrm{Ta}_{\mathrm{o}}\right)$ :

$$
T a_{o}=\frac{1}{8}\left[\frac{\rho w^{(2-n)}}{\eta_{0}}\right]^{2} D_{h}^{(2 n+1)} R_{i}^{(3-2 n)}
$$

onde $\mathrm{Ta} a_{o}$ representa o Número de Taylor original para um fluido Power-law quando a velocidade média do escoamento axial é nula $(\bar{U}=0)$.

- $\quad$ Razão de velocidade azimutal-axial (६):

$$
\xi=\frac{w R_{i}}{\bar{U}}
$$

onde $w$ representa a velocidade angular de rotação do cilindro interno. 
- Número de Reynolds modificado (Re):

$$
R e=\left(1+\xi^{2}\right)^{(1-n) / 2} R e_{o}
$$

- Número de Taylor modificado (Ta):

$$
T a=\left(\frac{1}{\xi^{2}}+1\right)^{(1-n)} T a_{o}
$$

\section{2 \\ Validação do modelo para caso Concêntrico}

Os resultados obtidos pelo modelo foram comparados com soluções analíticas disponíveis na literatura a fim de se validar a utilização das simplificações adotadas. Para isso, inicialmente considerou-se o escoamento de um fluido Newtoniano em espaço anular concêntrico sem rotação do cilindro interno. Neste caso, não há simplificações e o resultado obtido deve ser idêntico aos modelos de escoamento desenvolvido.

O cálculo da vazão volumétrica em função da diferença de pressão para um fluido Newtoniano em um espaço anular pode ser realizado através da solução analítica apresentada por Bird [26], e representada pela equação (3-1).

$$
Q_{\text {Newt.teórico }}=\frac{\pi(-d P d z) R_{o}^{4}}{8 \mu}\left[1-k^{4}-\frac{\left(1-k^{2}\right)^{2}}{\operatorname{Ln}\left(\frac{1}{k}\right)}\right]
$$

onde $k$ é a razão de raios do anular e $\mu$ é a viscosidade do fluido Newtoniano.

Para que o modelo apresente soluções para a hipótese de escoamento supracitada, é necessário que a função viscosidade power-law utilize índice de comportamento do fluido igual à viscosidade do fluido Newtoniano $(n=1)$. Com isso, o método da Viscosidade Newtoniana Equivalente não é fonte de erros, pois a viscosidade do fluido é conhecida e o modelo converge apenas com uma interação. 
A teoria da Lubrificação também não é fonte de erros para a hipótese de escoamento assumida, onde a componente axial da velocidade só varia ao longo da coordenada radial. Desta forma, não existem aproximações no modelo proposto, e a solução encontrada recupera a solução analítica de Bird [26] sem erros, conforme resultados apresentados na Tabela 3.

Tabela 3 - Solução concêntrica para Fluido Newtoniano $(n=1)$

\begin{tabular}{|c|c|c|c|}
\hline $\mathbf{k}$ & $\mathbf{Q}_{\text {Bird }}$ & $\mathbf{Q}_{\text {modelo }}$ & Erro \\
\hline 0,1 & 0,0052 & 0,0052 & $0,0 \%$ \\
\hdashline 0,2 & 0,0057 & 0,0057 & $0,0 \%$ \\
\hline 0,3 & 0,0061 & 0,0061 & $0,0 \%$ \\
\hline 0,4 & 0,0066 & 0,0066 & $0,0 \%$ \\
\hline 0,5 & 0,0071 & 0,0071 & $0,0 \%$ \\
\hline 0,6 & 0,0075 & 0,0075 & $0,0 \%$ \\
\hline 0,7 & 0,0080 & 0,0080 & $0,0 \%$ \\
\hline 0,8 & 0,0085 & 0,0085 & $0,0 \%$ \\
\hline 0,9 & 0,0090 & 0,0090 & $0,0 \%$ \\
\hline
\end{tabular}

onde $\beta$ é um parâmetro que é função da relação de raios do espaço anular $(k)$ e do índice de comportamento power-law $(n)$. A coordenada $\beta R_{0}$ é o ponto onde a tensão cisalhante é nula.

Neste caso, a utilização do método da viscosidade Newtoniana é necessária e considera-se como aproximação inicial da viscosidade para o processo iterativo o valor da viscosidade caso o fluido fosse Newtoniano. A teoria da Lubrificação continua não sendo fonte de erros, pois o escoamento no espaço anular é concêntrico e a componente axial da velocidade só varia ao longo da coordenada radial. 
A Tabela 4 apresenta os resultados do modelo para diferentes razões de raio $(k)$ e índice de comportamento do fluido $(n)$. O aumento do erro médio com o afastamento do comportamento Newtoniano pode ser atribuído ao método da Viscosidade Newtoniana Equivalente. O erro observado não é significativo quando comparado ao benefício de um menor custo computacional do modelo proposto, sendo assim, validado para esta hipótese de escoamento.

Tabela 4 - Solução concêntrica para Fluido não Newtoniano

\begin{tabular}{|c|c|c|c|c|c|c|}
\hline \multirow{2}{*}{ k } & \multicolumn{2}{|c|}{$n=0,8$} & \multicolumn{2}{|c|}{$n=0,5$} & \multicolumn{2}{|c|}{$n=0,2$} \\
\hline & $\mathbf{Q}_{\text {Bird }}$ & $\mathbf{Q}_{\text {modelo }}$ & $\mathbf{Q}_{\text {Bird }}$ & $\mathbf{Q}_{\text {modelo }}$ & $\mathbf{Q}_{\text {Bird }}$ & $\mathbf{Q}_{\text {modelo }}$ \\
\hline 0,1 & 0,0091 & 0,0091 & 0,0159 & 0,0160 & 0,0230 & 0,0232 \\
\hline 0,2 & 0,0095 & 0,0095 & 0,0160 & 0,0161 & 0,0226 & 0,0228 \\
\hline 0,3 & 0,0099 & 0,0099 & 0,0159 & 0,0160 & 0,0217 & 0,0219 \\
\hline 0,4 & 0,0101 & 0,0101 & 0,0154 & 0,0155 & 0,0204 & 0,0206 \\
\hline 0,5 & 0,0102 & 0,0102 & 0,0146 & 0,0147 & 0,0185 & 0,0188 \\
\hline 0,6 & 0,0101 & 0,0101 & 0,0134 & 0,0135 & 0,0162 & 0,0164 \\
\hline 0,7 & 0,0097 & 0,0097 & 0,0118 & 0,0119 & 0,0134 & 0,0135 \\
\hline 0,8 & 0,0090 & 0,0090 & 0,0095 & 0,0096 & 0,0099 & 0,0100 \\
\hline Erro Médio & \multicolumn{2}{|c|}{$0,0 \%$} & \multicolumn{2}{|c|}{$0,7 \%$} & \multicolumn{2}{|c|}{$1,0 \%$} \\
\hline
\end{tabular}

\section{3 \\ Validação do modelo para caso Excêntrico}

A fim de se comparar os resultados do modelo proposto com a solução numérica apresentada por Escudier [16] no ano de 2002, adotou-se o escoamento laminar de um fluido Power-law no espaço anular com excentricidade constante ao longo da direção axial. Nesta configuração o campo de velocidade apresenta somente componente axial, sendo esta uma função das coordenadas radial e azimutal. A variação da componente da velocidade com a coordenada azimutal é principalmente influenciada pela magnitude da excentricidade do cilindro interno. A solução apresentada por Escudier representa a solução completa dos campos de velocidade axial e azimutal do escoamento desenvolvido de um fluido Power-law em um espaço anular.

O produto $f$. Re será utilizado para poder comparar os resultados do modelo com a solução numérica de Escudier [16]. Os parâmetros de excentricidade adimensional $(\varepsilon)$, índice de comportamento do fluido $(n)$ e razão de raios no espaço anular $(k)$ serão avaliados. 
A Figura 16 apresenta a influência da excentricidade no produto $f$.Re para todos os diferentes índices de comportamento do fluido analisados para uma mesma razão de raios $(k=0,5)$ e sem rotação do cilindro interno. A figura apresenta os resultados obtidos pelo modelo simplificado apresentado neste trabalho e do modelo completo de Escudier.

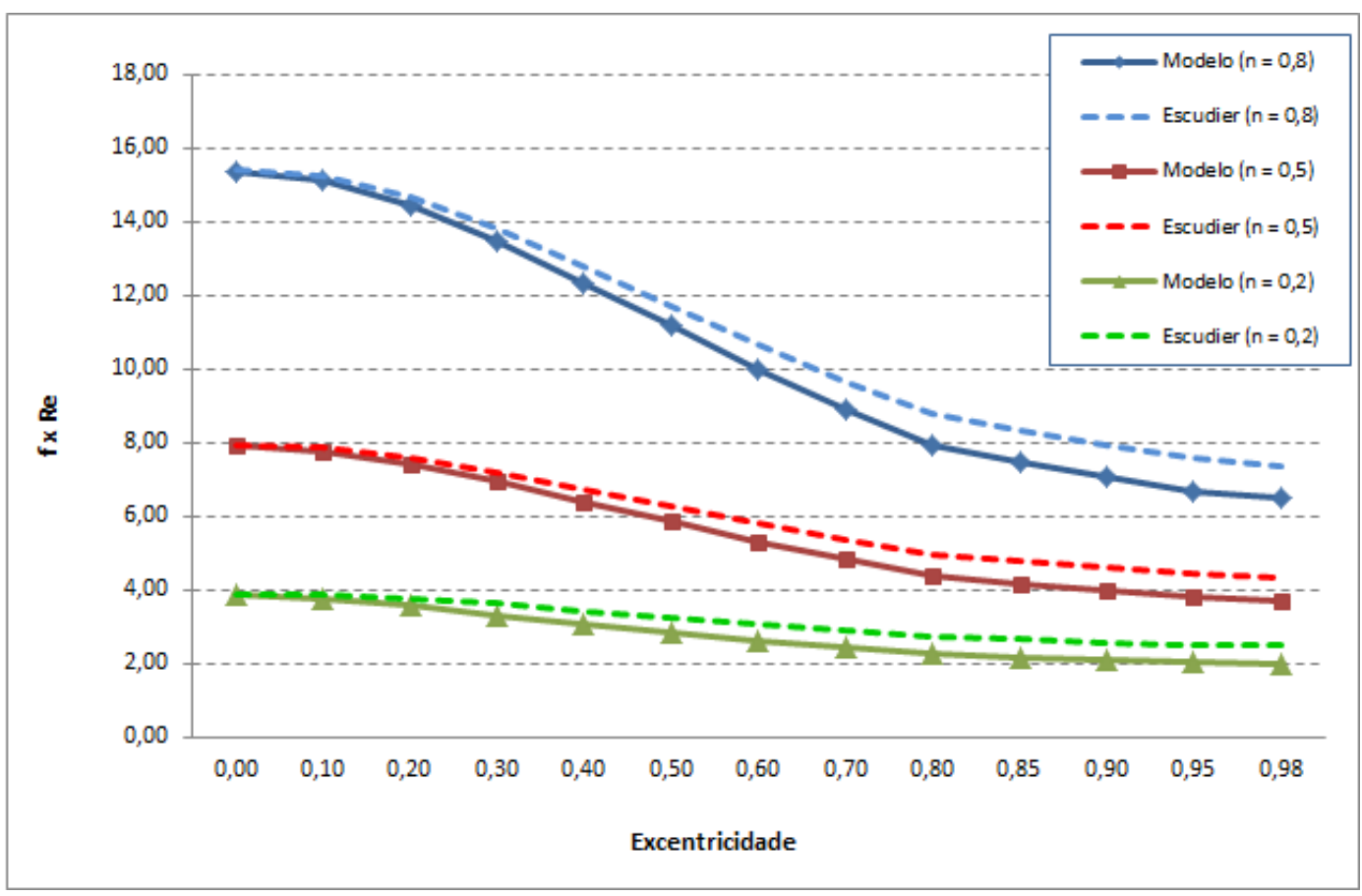

Figura 16 - Influência da excentricidade no comportamento do produto $f$. Re em fluidos não Newtonianos e sem rotação do cilindro interno.

O gráfico mostra o decréscimo da perda de carga com o aumento da excentricidade devido à diminuição do espaço de folga radial mínima, resultando no escoamento de maior parte do fluido na região de maior folga radial.

Para os parâmetros utilizados, é possível observar que a curva do modelo proposto está de acordo com a solução numérica obtida por Escudier e apresenta um erro numérico máximo de $1 \%$ para o caso de escoamento em anular concêntrico, atribuído à utilização do método da Viscosidade Newtoniana Equivalente. $\mathrm{O}$ aumento da excentricidade resulta em um aumento do erro do modelo proposto, podendo chegar a um erro de $20 \%$ nos casos com excentricidade de 0,98 e grande afastamento do comportamento Newtoniano, $n=0,2$, conforme dados apresentados na Tabela 5 . 
Tabela 5 - Solução com espaço anular excêntrico para Fluido não Newtoniano

\begin{tabular}{|c|c|c|c|c|c|c|c|c|c|c|c|}
\hline \multirow{3}{*}{$\mathbf{k}$} & \multirow{3}{*}{$\mathrm{Ta}$} & \multirow{3}{*}{$\varepsilon$} & \multicolumn{3}{|c|}{$\mathrm{n}=0,8$} & \multicolumn{3}{|c|}{$n=0,5$} & \multicolumn{3}{|c|}{$n=0,2$} \\
\hline & & & \multicolumn{2}{|c|}{ f.Re } & \multirow[b]{2}{*}{ Erro } & \multicolumn{2}{|c|}{ f.Re } & \multirow[b]{2}{*}{ Erro } & \multicolumn{2}{|c|}{ f.Re } & \multirow[b]{2}{*}{ Erro } \\
\hline & & & Modelo & Escudier & & Modelo & Escudier & & Modelo & Escudier & \\
\hline 0,5 & 0 & 0,00 & 15,3904 & 15,4380 & $0 \%$ & 7,9194 & 7,9468 & $0 \%$ & 3,8650 & 3,8874 & $1 \%$ \\
\hline 0,5 & 0 & 0,10 & 15,1128 & 15,2360 & $1 \%$ & 7,7745 & 7,8572 & $1 \%$ & 3,7742 & 3,8699 & $2 \%$ \\
\hline 0,5 & 0 & 0,20 & 14,4343 & 14,6630 & $2 \%$ & 7,4271 & 7,5955 & $2 \%$ & 3,5686 & 3,7776 & $6 \%$ \\
\hline 0,5 & 0 & 0,30 & 13,4668 & 13,8110 & $2 \%$ & 6,9464 & 7,2048 & $4 \%$ & 3,3178 & 3,6160 & $8 \%$ \\
\hline 0,5 & 0 & 0,40 & 12,3374 & 12,7940 & $4 \%$ & 6,4041 & 6,7428 & $5 \%$ & 3,0670 & 3,4223 & $10 \%$ \\
\hline 0,5 & 0 & 0,50 & 11,1623 & 11,7190 & $5 \%$ & 5,8565 & 6,2605 & $6 \%$ & 2,8347 & 3,2261 & $12 \%$ \\
\hline 0,5 & 0 & 0,60 & 10,0048 & 10,6590 & $6 \%$ & 5,3255 & 5,7895 & $8 \%$ & 2,6185 & 3,0403 & $14 \%$ \\
\hline 0,5 & 0 & 0,70 & 8,9256 & 9,6656 & $8 \%$ & 4,8351 & 5,3510 & $10 \%$ & 2,4234 & 2,8740 & $16 \%$ \\
\hline 0,5 & 0 & 0,80 & 7,9509 & 8,7619 & $9 \%$ & 4,3946 & 4,9518 & $11 \%$ & 2,2501 & 2,7160 & $17 \%$ \\
\hline 0,5 & 0 & 0,85 & 7,4761 & 8,3463 & $10 \%$ & 4,1801 & 4,7675 & $12 \%$ & 2,1658 & 2,6446 & $18 \%$ \\
\hline 0,5 & 0 & 0,90 & 7,0881 & 7,9549 & $11 \%$ & 4,0036 & 4,5932 & $13 \%$ & 2,0962 & 2,5768 & $19 \%$ \\
\hline 0,5 & 0 & 0,95 & 6,6786 & 7,5872 & $12 \%$ & 3,8144 & 4,4286 & $14 \%$ & 2,0211 & 2,5123 & $20 \%$ \\
\hline 0,5 & 0 & 0,98 & 6,4849 & 7,3776 & $12 \%$ & 3,7244 & 4,3342 & $14 \%$ & 1,9853 & 2,4752 & $20 \%$ \\
\hline & & & \multicolumn{2}{|c|}{ Erro médio } & $6,3 \%$ & \multicolumn{2}{|c|}{ Erro médio } & $7,7 \%$ & \multicolumn{2}{|c|}{ Erro médio } & $12,5 \%$ \\
\hline
\end{tabular}

A inclusão da rotação do cilindro interno no escoamento em espaço anular com excentricidade constante ao longo da componente axial resulta em problemas de convergência do modelo, que irá depender da velocidade de rotação do cilindro interno e do afastamento do fluido do comportamento Newtoniano.

As diferentes velocidades de rotação do cilindro interno são representadas pelo parâmetro adimensional número de Taylor $(\mathrm{T} a)$.

A Figura 17 apresenta a comparação dos resultados do modelo proposto com a solução numérica de Escudier [16] na presença de baixa velocidade de rotação do cilindro interno $(T a=10)$.

O produto $f$.Re apresenta o mesmo comportamento de redução com o aumento da excentricidade, apresentado no caso sem rotação do cilindro interno. Entretanto, para baixas velocidades de rotação o modelo não convergiu nos casos de grande afastamento do comportamento Newtoniano $(n=0,2)$ e excentricidade maior que 0,4 .

Neste caso, a simplificação da Viscosidade Newtoniana Equivalente e a teoria da Lubrificação são fontes de erro ao modelo. No caso do método da Viscosidade Newtoniana Equivalente, o modelo perde precisão com o afastamento do comportamento Newtoniano, conforme observado anteriormente. Além disso, a simplificação da teoria da Lubrificação não considera os efeitos da 
força inercial no escoamento, parâmetro este importante na análise da influência da rotação do cilindro interno na hipótese de escoamento assumida.

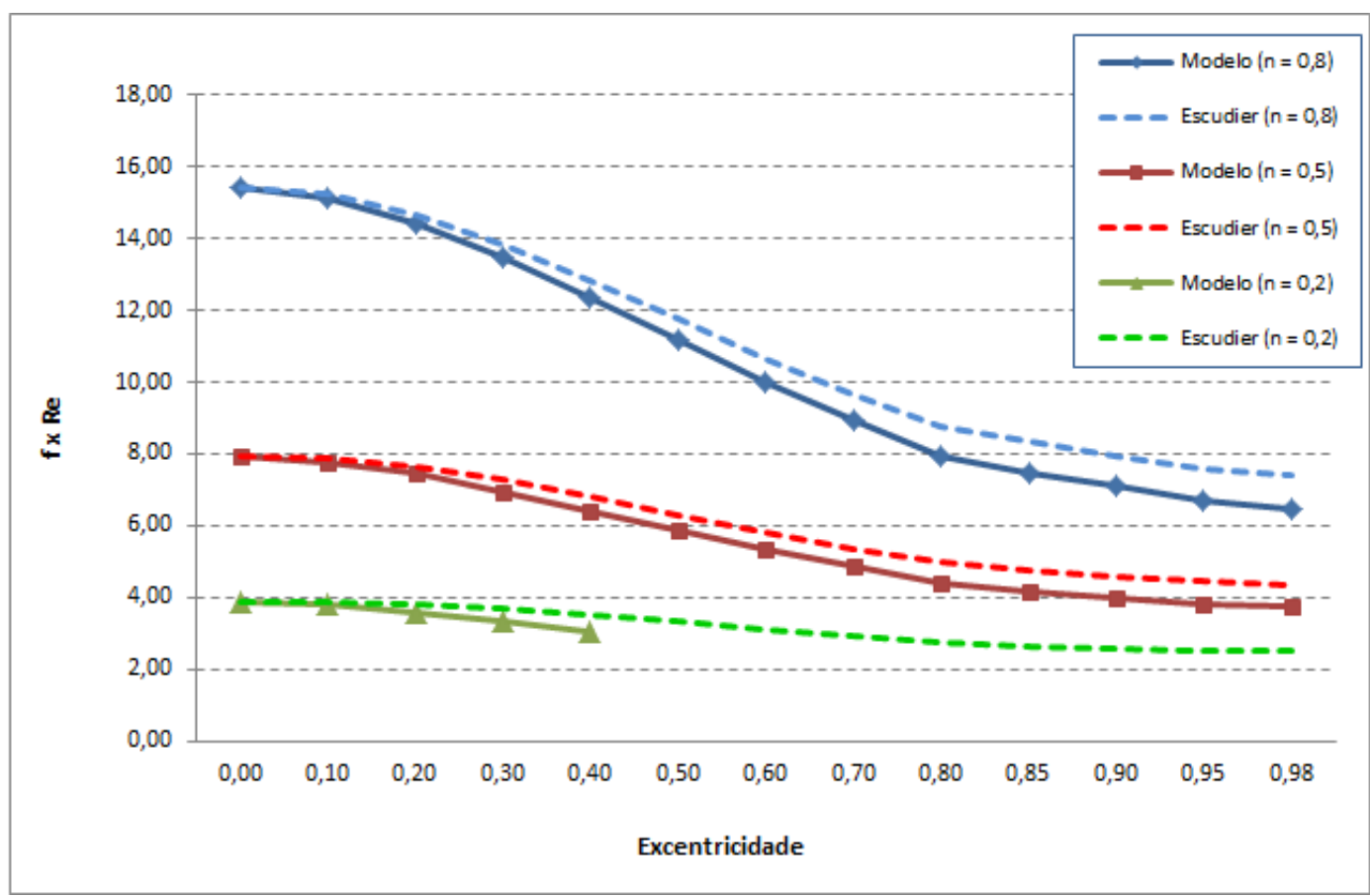

Figura 17 - Influência da excentricidade no comportamento do produto $f$. $R e$ em fluidos não Newtonianos com rotação do cilindro interno $(\mathrm{Ta}=10)$.

O aumento da velocidade de rotação do cilindro interno $(T a=100)$, representado na Figura 18, resulta em problemas de convergência não só para fluidos com grande afastamento do comportamento Newtoniano $(n=0,2)$ apresentados anteriormente, como também para fluidos apresentando $n=0,5 \mathrm{e}$ excentricidade superior a 0,6 .

O aumento do erro do modelo proposto com o aumento da velocidade de rotação do cilindro interno pode ser justificado pelo aumento da importância dos efeitos inerciais no escoamento. As recirculações que aparecem na seção no caso de altas velocidades de rotação e excentricidade podem alterar a relação vazãogradiente de pressão.

A utilização do modelo proposto no caso de fluidos com $n>0,5$, e valores de $T a \leq 1000$ é favorável devido seu menor custo computacional, comparado com a solução analítica de Escudier. Os resultados do modelo e a comparação com a solução de Escudier são apresentados na Figura 19. 


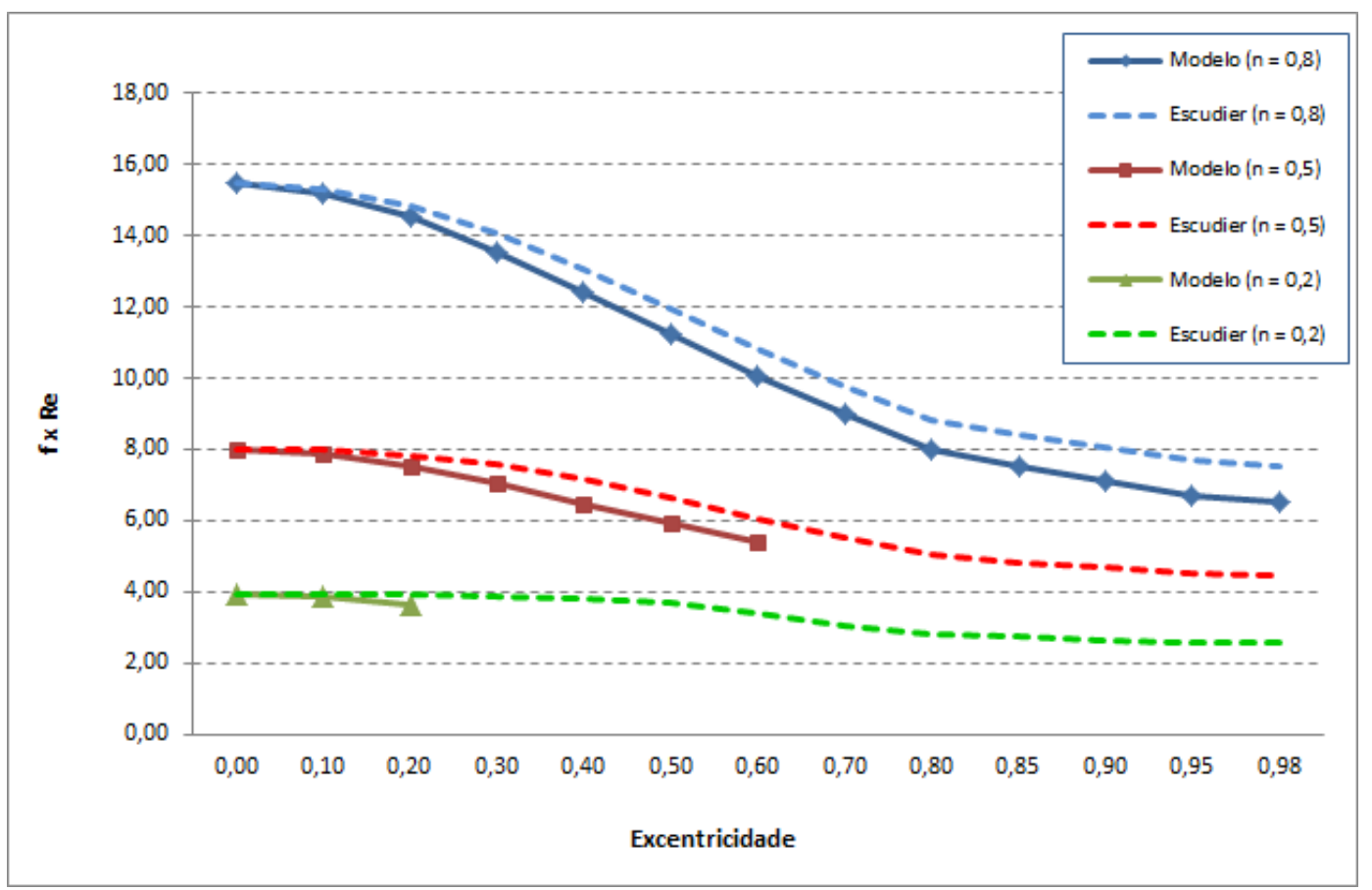

Figura 18 - Influência da excentricidade no comportamento do produto $f$. Re em fluidos não Newtonianos com rotação do cilindro interno $(\mathrm{Ta}=100)$.

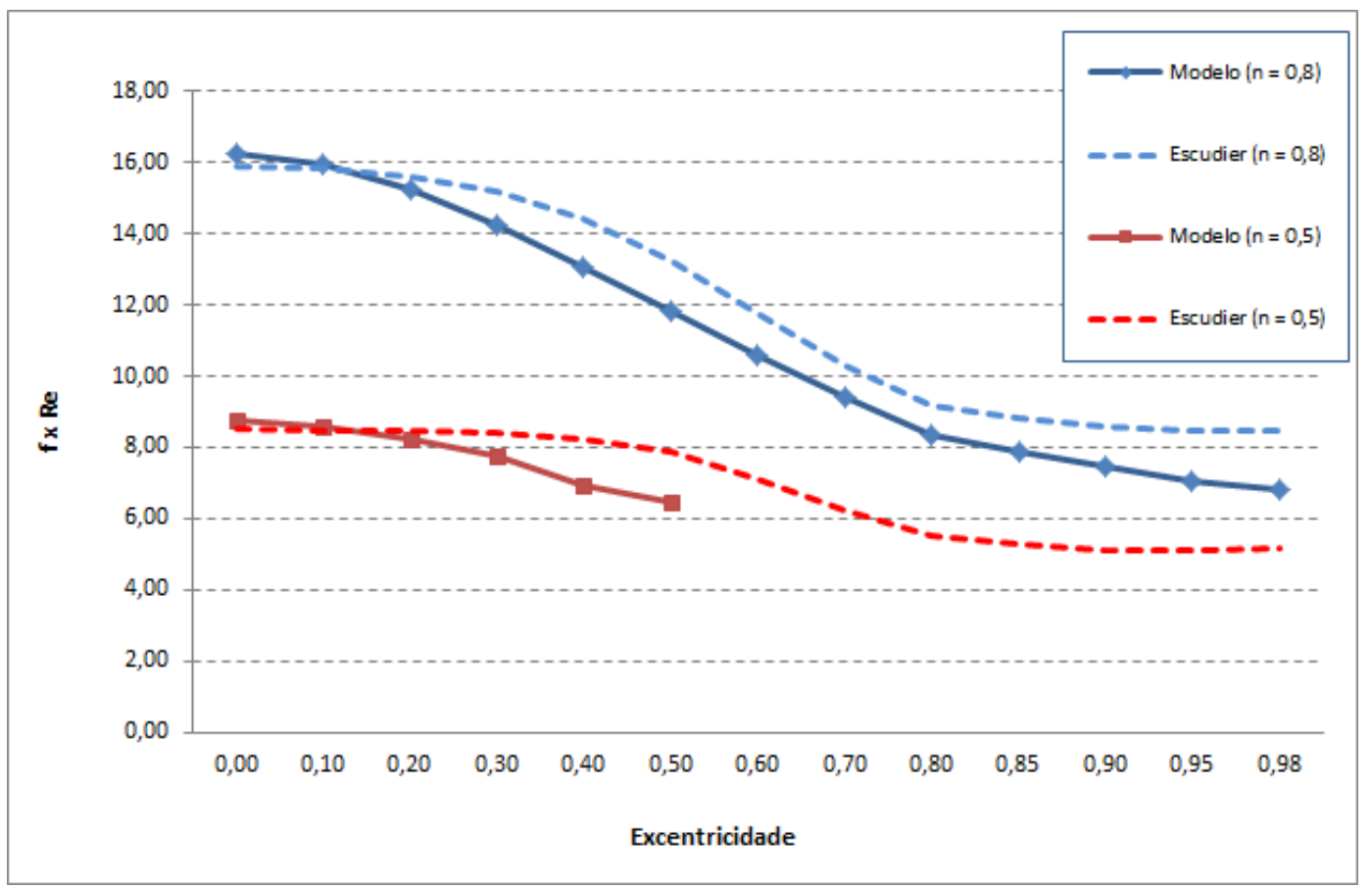

Figura 19 - Influência da excentricidade no comportamento do produto $f$. Re em fluidos não Newtonianos com rotação do cilindro interno $(\mathrm{Ta}=1000)$. 
Para os casos de $T a \geq 10000$ os erros do modelo devido à simplificação da teoria da Lubrificação passam a superar os benefícios de se ter um modelo de baixo custo computacional, representados pela Figura 20 .

A comparação dos valores obtidos pelo modelo proposto com a solução numérica de Escudier não é relevante para $T a \geq 10000$. Nesses casos, a hipótese de escoamento desenvolvido não pode ser utilizada devido presença dos vórtices de Taylor. Sendo assim, os valores obtidos pela solução numérica de Escudier também não são precisos.

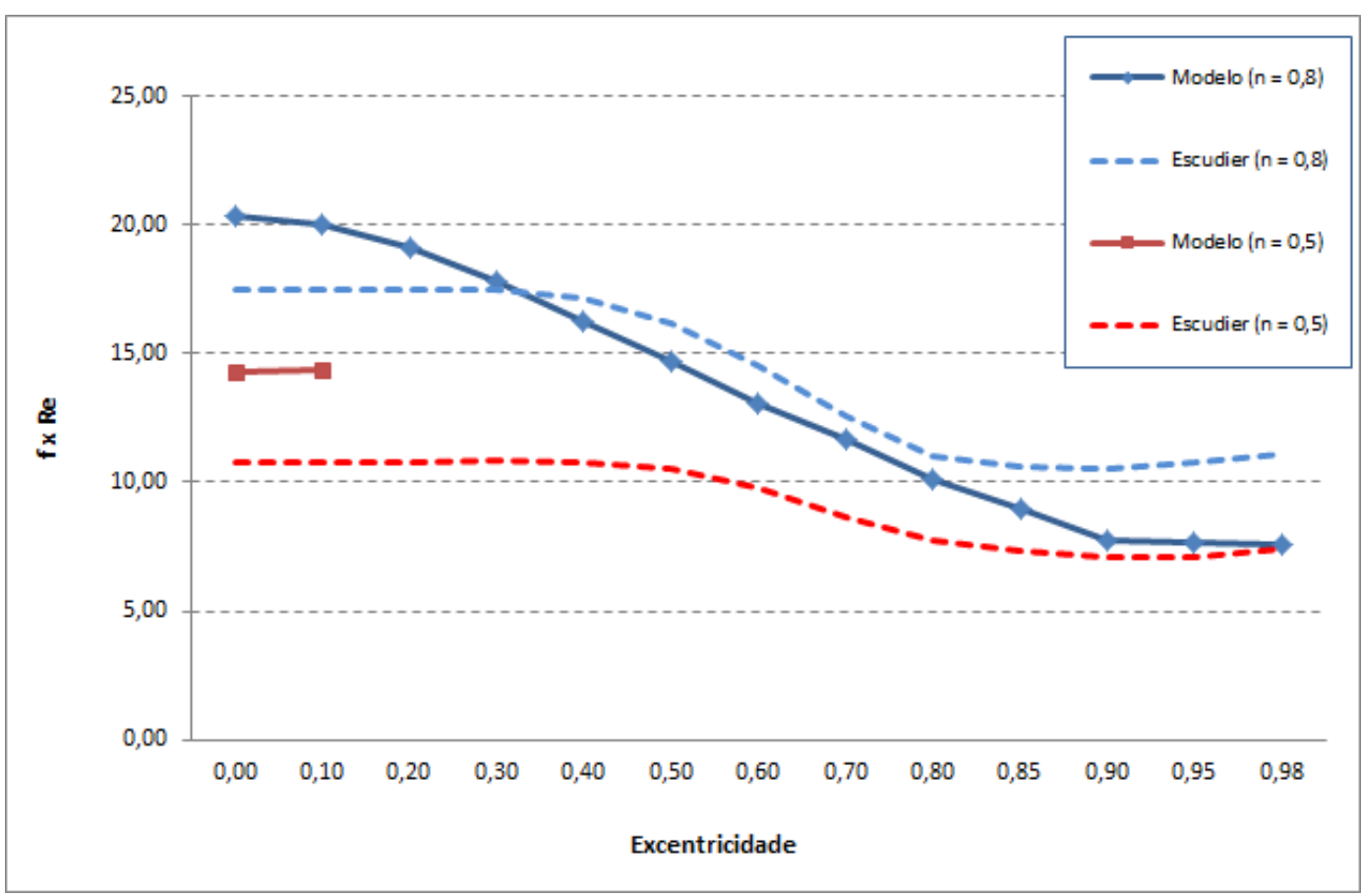

Figura 20 - Influência da excentricidade no comportamento do produto $f$. Re em fluidos não Newtonianos com rotação do cilindro interno $(\mathrm{Ta}=10000)$.

\section{4}

\section{Efeitos da razão de raios no escoamento}

A Figura 21 apresenta a influência da razão de raios $(k)$ no produto $f$. $R e$, em um escoamento em espaço anular concêntrico sem rotação do cilindro interno, e fluidos com diferentes índices de comportamento power-law (n). A partir dos resultados do modelo pode-se concluir que a influência do parâmetro razão de raios no produto $f$.Re é quase nula, podendo assim ser considerado desprezível nos casos de escoamento concêntrico. 
A diminuição da perda de carga com o afastamento do comportamento Newtoniano pode ser atribuída ao efeito da redução da viscosidade do fluido com a taxa de cisalhamento.

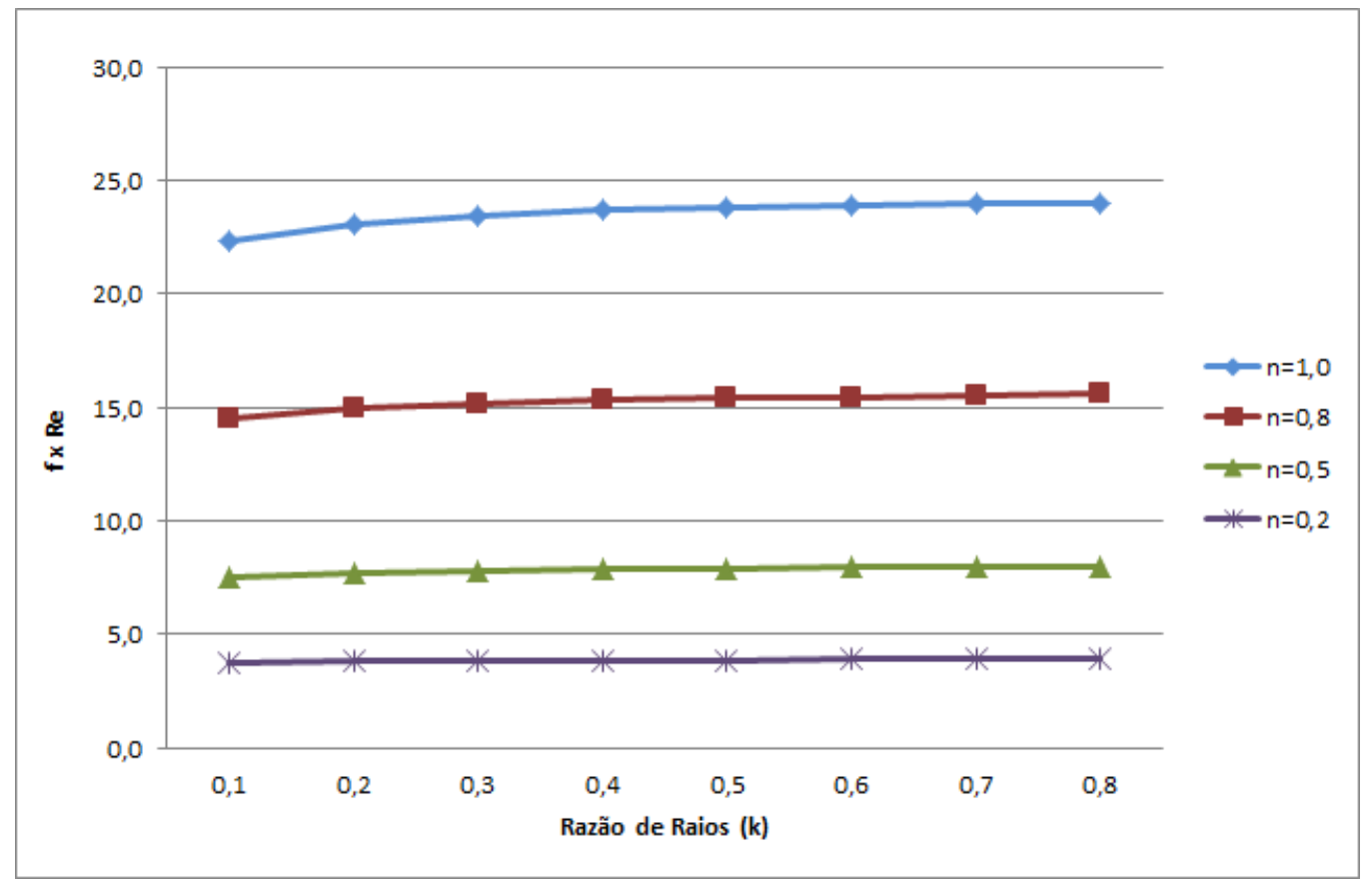

Figura 21 - Influencia da razão de raios no produto $f$. Re para escoamento de fluido com comportamento não Newtoniano.

\section{5 \\ Efeitos da excentricidade no escoamento}

Como já descrito anteriormente, um fluido Newtoniano possui viscosidade constante e independente da tensão de deformação, entretanto, é possível observar na Figura 22 a diminuição do produto $f$. Re com o aumento da excentricidade. Este fenômeno pode ser explicado pelo aumento da vazão volumétrica com o afastamento do cilindro interno para um dado gradiente de pressão, ou seja, ocorrência de um escoamento preferencial nas regiões de maior folga radial.

A Figura 23 apresenta a influência da excentricidade para diferentes fluidos em um escoamento em espaço anular sem rotação do cilindro interno. $\mathrm{O}$ efeito de redução do produto $f$. Re com o aumento da excentricidade observado em fluidos Newtonianos também ocorre com o afastamento do comportamento Newtoniano (índice de potência, $n$ ). Entretanto, quanto menor o índice de potência, menor será 
a perda de carga no escoamento. Este fenômeno pode ser explicado pelo efeito da tensão de cisalhamento nos fluidos não Newtonianos, reduzindo a viscosidade do fluido presente no espaço anular, e consequentemente reduzindo a perda de carga no escoamento.

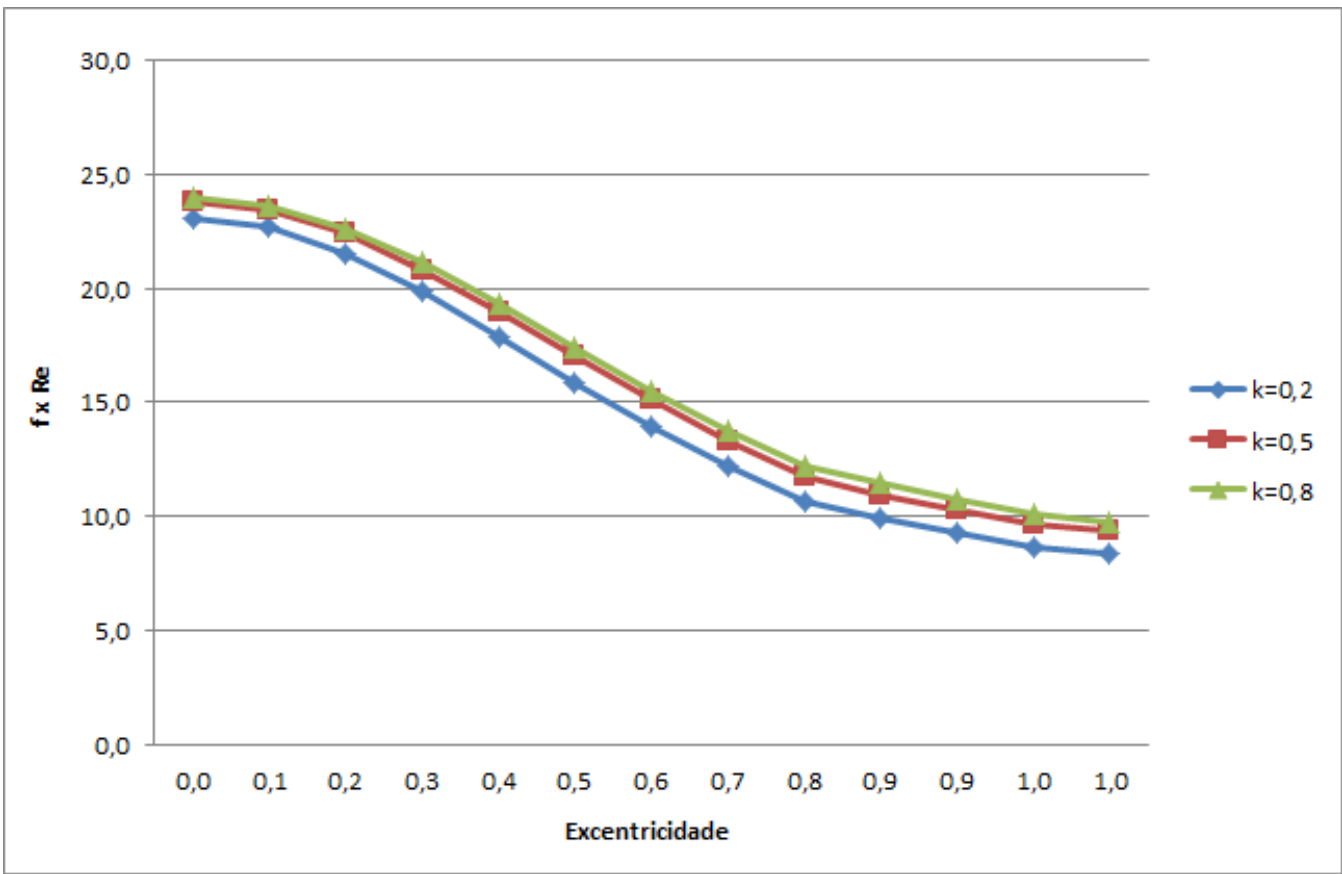

Figura 22 - Influencia da excentricidade no produto $f$. $R e$, e diferentes razões de raios $(k)$.

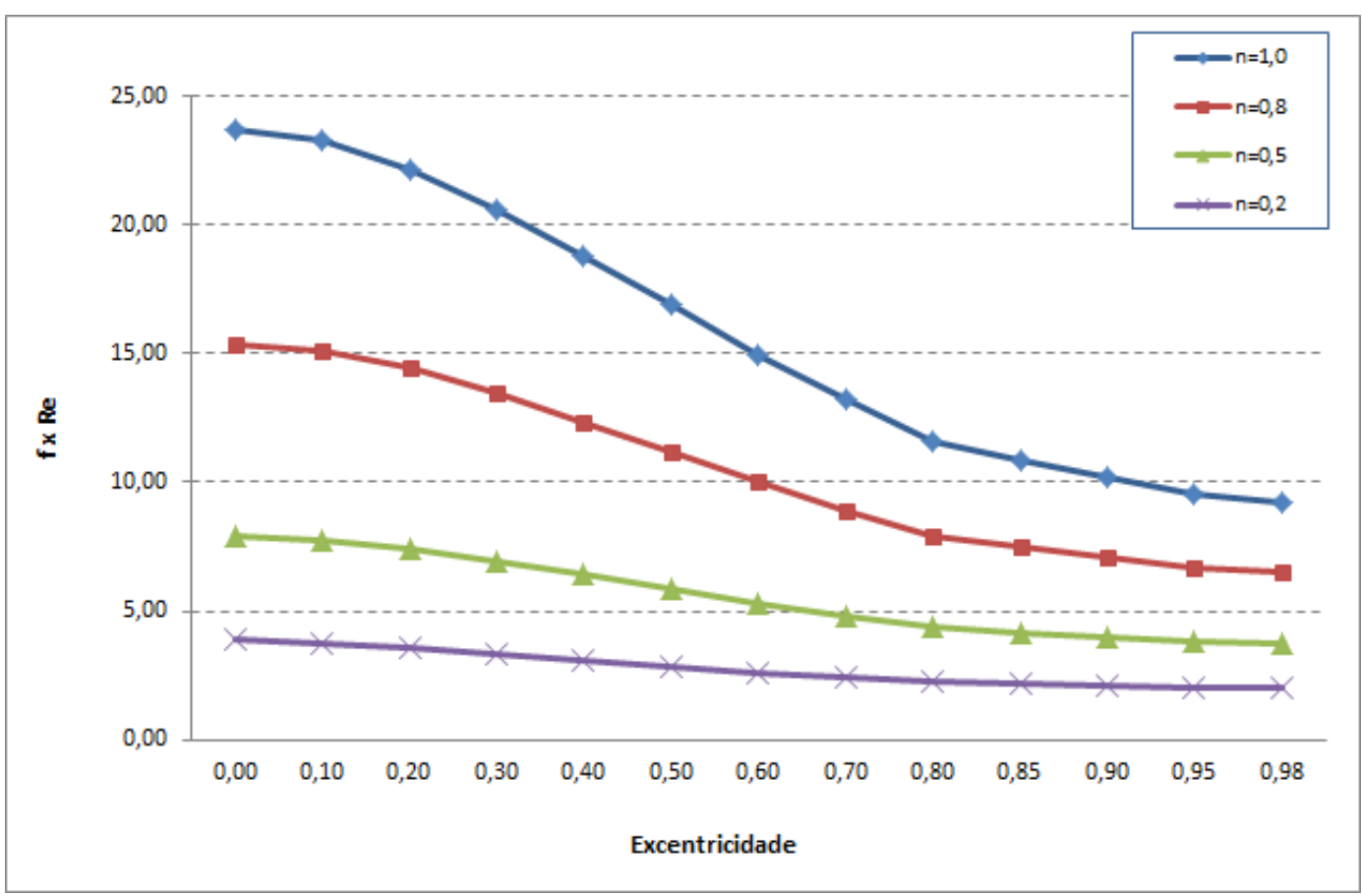

Figura 23 - Influencia da excentricidade no produto $f$. Re para fluidos com diferentes índices de potência $(n)$. 
A Figura 24 apresenta a relação do produto $f \cdot R e$ com a excentricidade para diferentes razões de raios $(k)$ e $n=0,5$. As curvas para razões de raios menores ou iguais a 0,7 apresentam o comportamento esperado, com redução do produto $f \cdot R e$ à medida que a excentricidade aumenta. Entretanto, a curva para $k=0,8$ apresenta um comportamento suspeito para as excentricidades contidas na faixa de 0,1 a 0,6. Este erro é devido ao método da Viscosidade Newtoniana Equivalente, e ao parâmetro global de vazão volumétrica o qual é atrelada a convergência. Em altas razões de raios, uma pequena mudança da excentricidade altera muito o valor da viscosidade. Com isso, a convergência da vazão volumétrica pode ter sido obtida sem ter ocorrido convergência da viscosidade calculada.

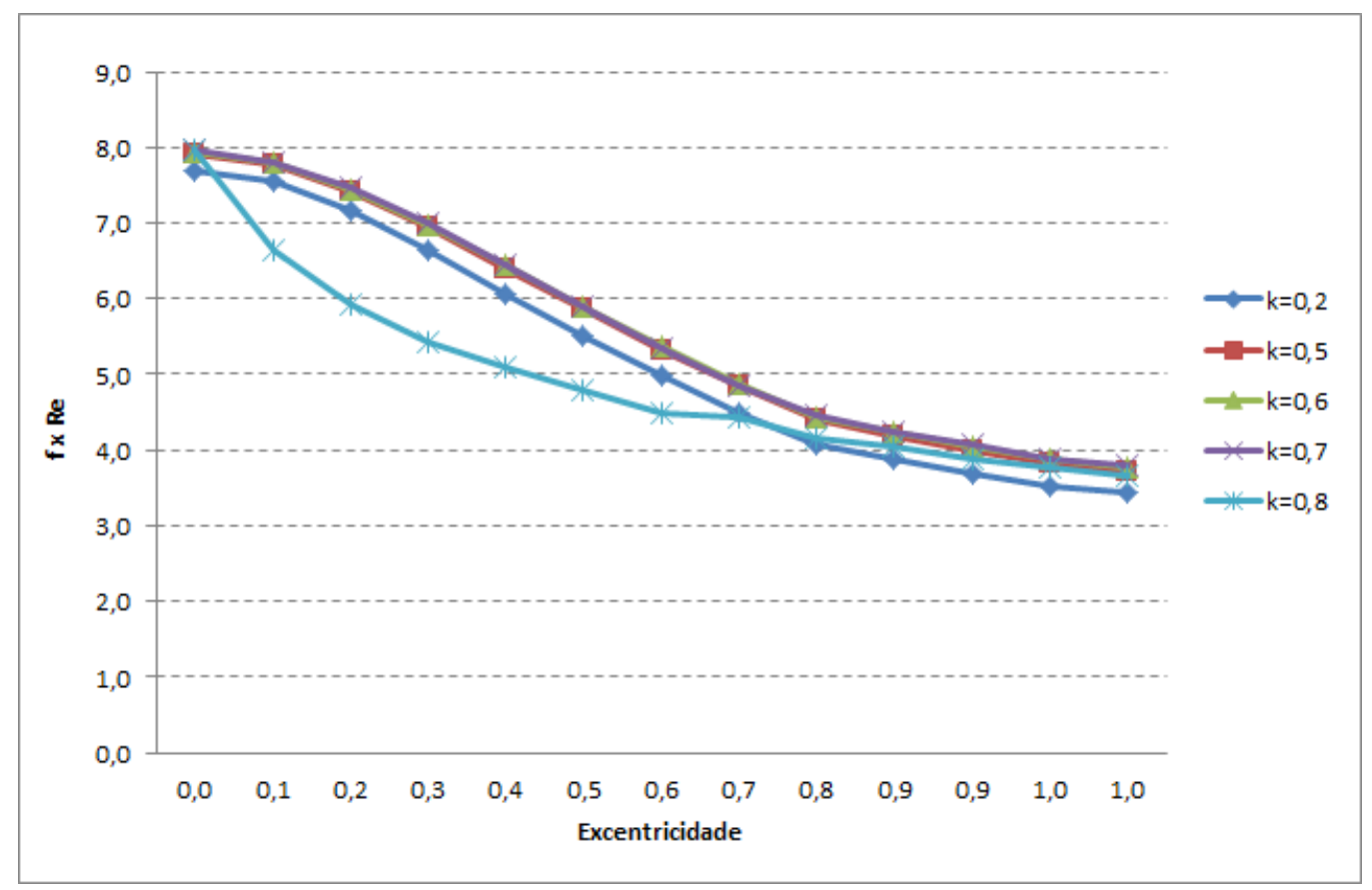

Figura 24 - Influencia da excentricidade no produto $f$. Re de um fluido não Newtoniano $(n=0,5)$.

\section{6}

\section{Efeitos da Rotação do cilindro interno no escoamento}

A influência da rotação do cilindro interno em um escoamento em espaço anular ocorre com o aumento da taxa de deformação, resultando na redução da viscosidade no caso de fluidos com comportamento não Newtoniano. Sendo assim, para o caso de escoamento de fluidos Newtonianos onde a viscosidade é 
constante, e independe da tensão de cisalhamento, espera-se que o produto $f$. Re permaneça inalterado na presença da rotação do cilindro interno.

A Figura 25 apresenta os resultados do modelo quando se utilizou a opção de fluido Newtoniano com viscosidade constante conhecida $(\mu=0,1)$, sem necessidade da utilização do método da Viscosidade Newtoniana Equivalente. Esta solução recupera o comportamento esperado pelos diversos estudos disponíveis na literatura, apresentando variações desprezíveis do produto $f$. Re com a rotação do cilindro interno.

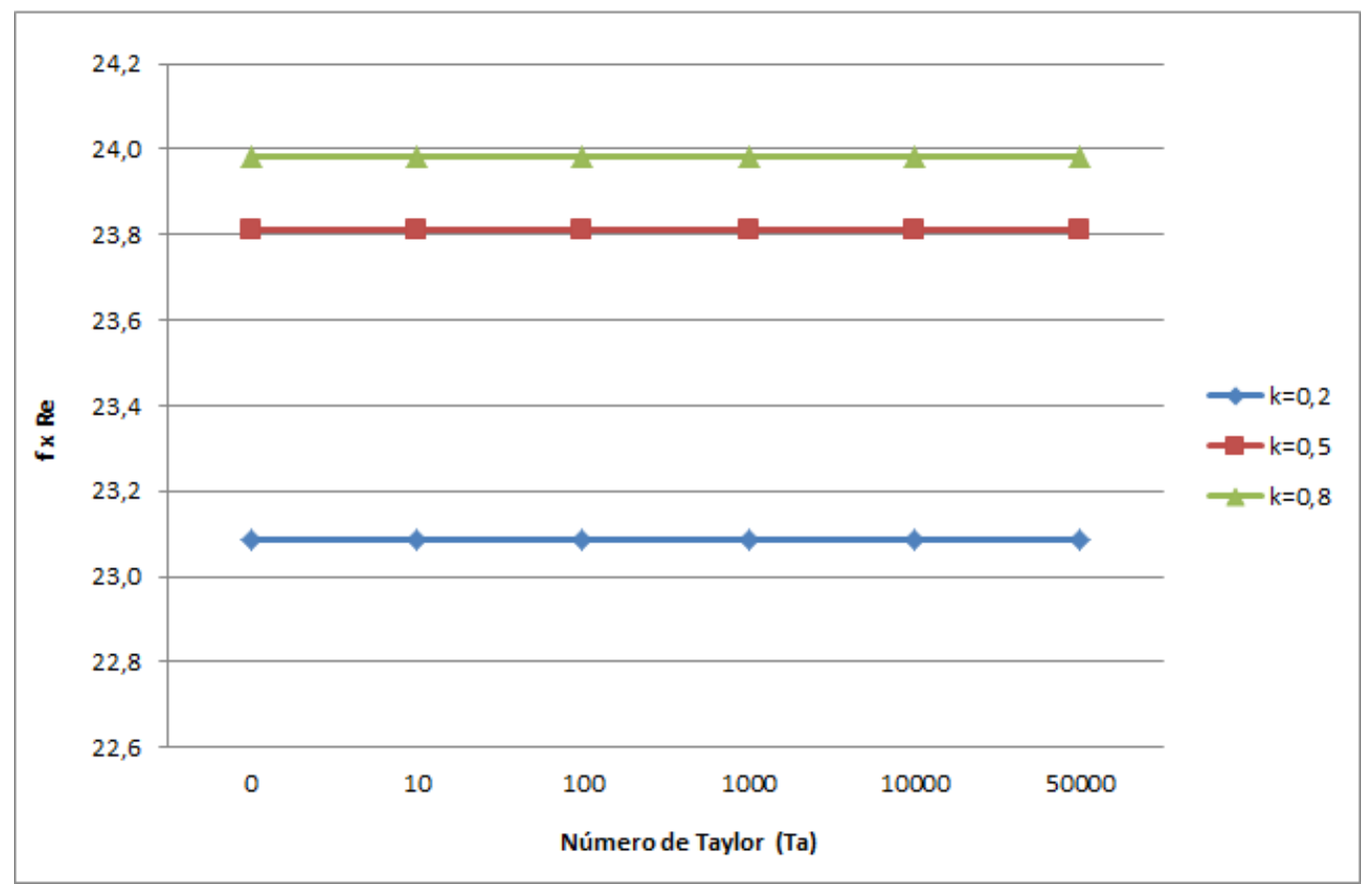

Figura 25 - Escoamento de um fluido Newtoniano em espaço anular concêntrico com rotação do cilindro interno, para diferentes razões de raios $(k)$.

Em contrapartida, a Figura 26 apresenta os resultados do modelo quando se utilizou a opção de fluido não Newtoniano com índice de potência para fluido Newtoniano $(n=1)$. Os valores obtidos pelo método da Viscosidade Equivalente Newtoniana nas diferentes velocidades de rotação do cilindro interno são apresentados na Tabela 6. Uma análise dos resultados permite concluir que o cálculo das tensões de cisalhamento no modelo é muito sensível a pequenas variações do valor de viscosidade, especialmente para altas velocidades de rotação do cilindro interno. 
$\mathrm{O}$ afastamento do valor esperado do produto $f$. Re ocorre na faixa de altas velocidades de rotação do cilindro interno ( $T a \geq 10000)$. Esta região apresentou perda de precisão do modelo na seção de validação apresentada anteriormente. Sendo assim, os resultados obtidos para $T a<1000$ podem ser utilizados sem comprometimento da precisão do modelo.

Comparando-se os efeitos da rotação do cilindro interno para as diferentes razões de raios $(k)$ na faixa de precisão do modelo, é possível observar o mesmo efeito apresentado anteriormente para um fluido Newtoniano. $\mathrm{O}$ efeito da variação da razão de raios $(k)$ não é significativo no produto $f$. Re, podendo ser desprezado.

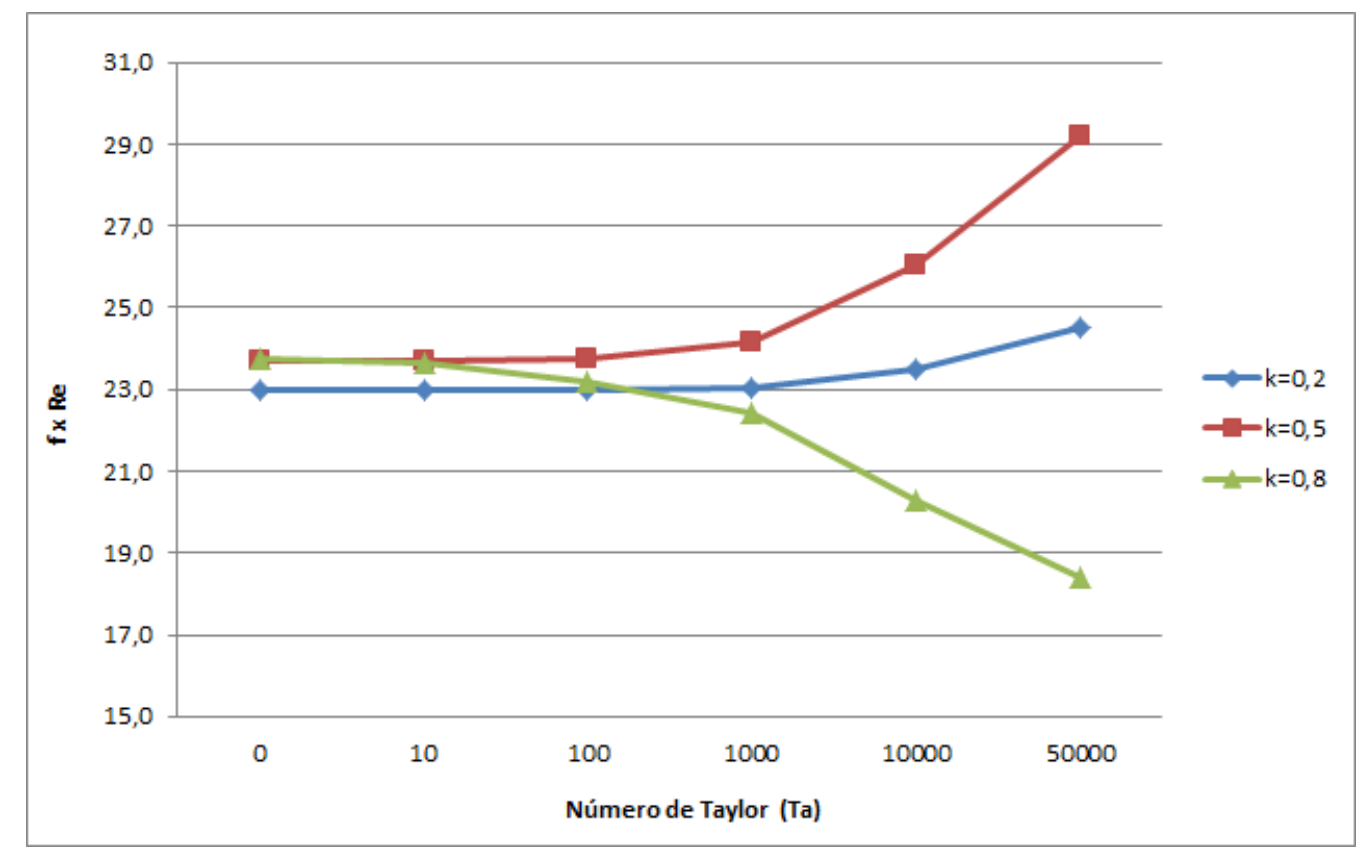

Figura 26 - Escoamento de um fluido Newtoniano em espaço anular concêntrico com rotação do cilindro interno, para diferentes razões de raios $(k)$.

Tabela 6 - Solução com espaço anular excêntrico para Fluido não Newtoniano

\begin{tabular}{|c|c|c|c|c|c|c|c|c|c|}
\hline \multirow{2}{*}{ Ta } & \multicolumn{3}{|c|}{$\mathbf{k = 0 , 2}$} & \multicolumn{3}{c|}{$\mathbf{k = 0 , 5}$} & \multicolumn{3}{|c|}{$\mathbf{k = 0 , 8}$} \\
& $\mathbf{f x R e}$ & $\mathbf{Q}$ & $\boldsymbol{\mu}$ & $\mathbf{f x R e}$ & $\mathbf{Q}$ & $\boldsymbol{\mu}$ & $\mathbf{f x R e}$ & $\mathbf{Q}$ & $\boldsymbol{\mu}$ \\
\hline 0 & 23,00 & 0,0057 & 0,0996 & 23,71 & 0,0071 & 0,0996 & 23,76 & 0,0085 & 0,0991 \\
\hline 10 & 23,00 & 0,0057 & 0,0996 & 23,72 & 0,0071 & 0,0996 & 23,62 & 0,0085 & 0,0985 \\
\hline 100 & 23,01 & 0,0057 & 0,0996 & 23,77 & 0,0071 & 0,0998 & 23,19 & 0,0085 & 0,0967 \\
\hline 1000 & 23,05 & 0,0057 & 0,0998 & 24,14 & 0,0071 & 0,1014 & 22,40 & 0,0085 & 0,0934 \\
\hline 10000 & 23,48 & 0,0057 & 0,1017 & 26,04 & 0,0071 & 0,1094 & 20,29 & 0,0085 & 0,0846 \\
\hline 50000 & 24,52 & 0,0057 & 0,1062 & 29,18 & 0,0071 & 0,1226 & 18,39 & 0,0085 & 0,0767 \\
\hline
\end{tabular}


A Figura 27 apresenta os resultados do modelo para um escoamento em espaço anular excêntrico de um fluido Newtoniano para diferentes razões de raios e velocidades de rotação do cilindro interno. Como o fluido é Newtoniano, a viscosidade e consequentemente o produto $f$. Re não variam com a rotação do cilindro interno. Entretanto, é possível observar diminuição do produto $f$. Re com o aumento da excentricidade, devido ao escoamento preferencial na região de maior folga radial.

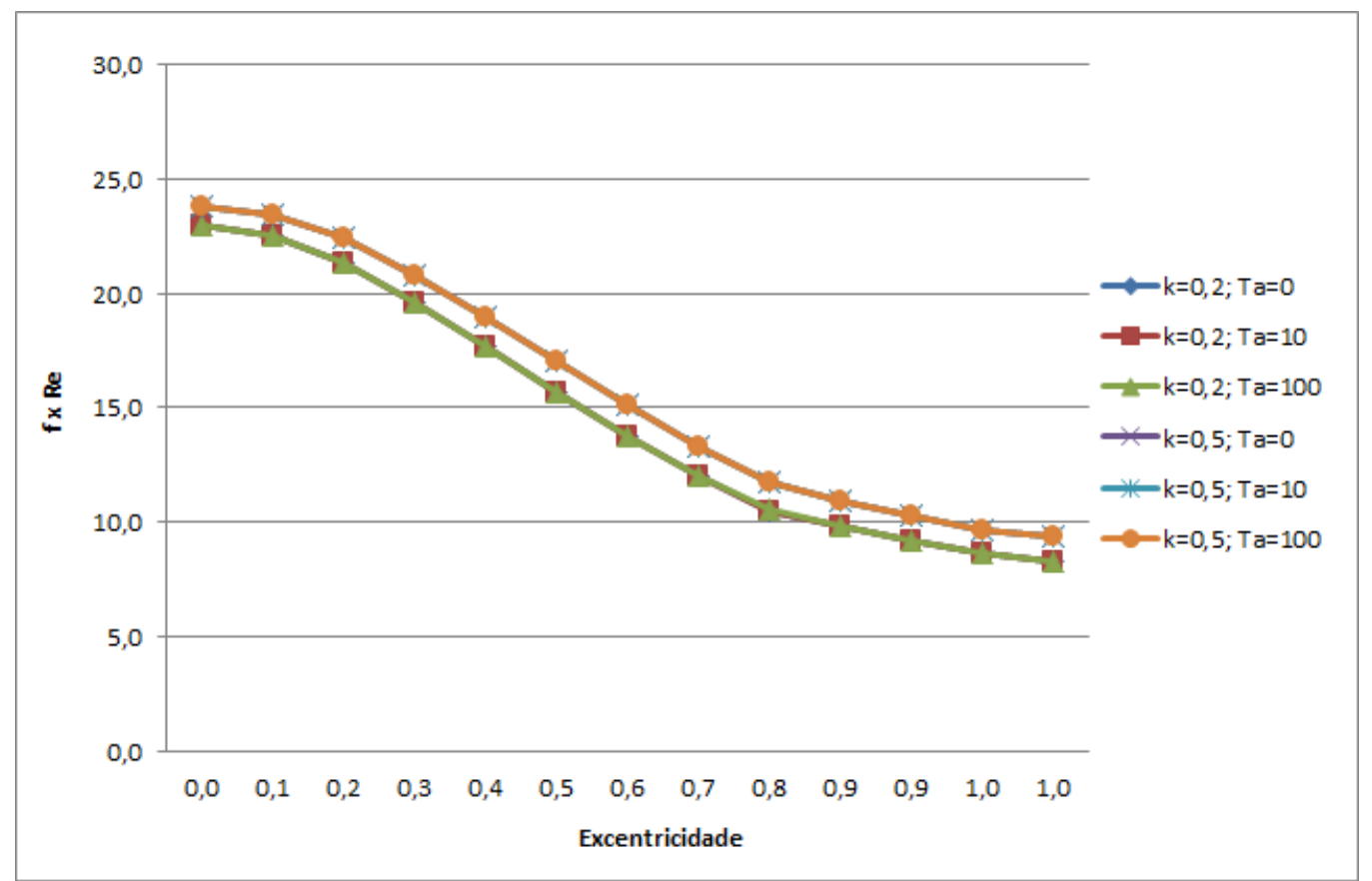

Figura 27 - Influencia da rotação do cilindro interno e da razão de raios $(k)$ no escoamento de um fluido Newtoniano.

No caso dos fluidos não Newtonianos, o aumento da velocidade de rotação do cilindro interno (Número de Taylor) unido ao aumento da excentricidade irá resultar no aparecimento de zonas de recirculação na região de maior folga radial. Nas regiões de recirculação têm-se aumento da viscosidade do fluido, resultando no aumento do produto $f$. Re, conforme pode ser observado na Figura 28.

A Figura 29, Figura 30 e Figura 31 apresentam os resultados do modelo proposto comparados com a solução numérica apresentada por Escudier. O intervalo de número de Taylor $(\mathrm{Ta}<1000)$ onde o modelo foi validado apresenta resultados confiáveis e que recuperam a solução completa de Escudier. 


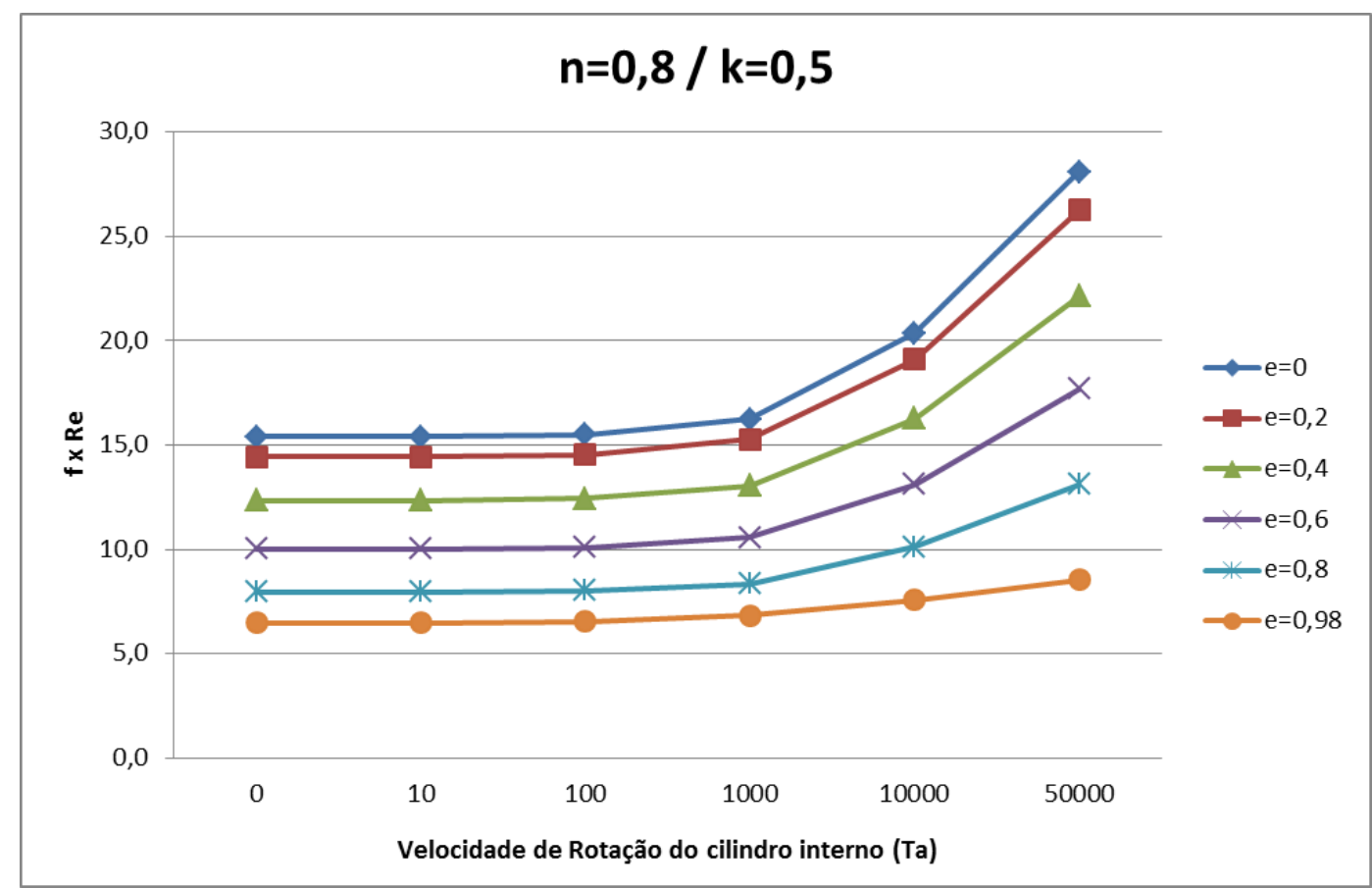

Figura 28 - Influência da rotação no comportamento do escoamento

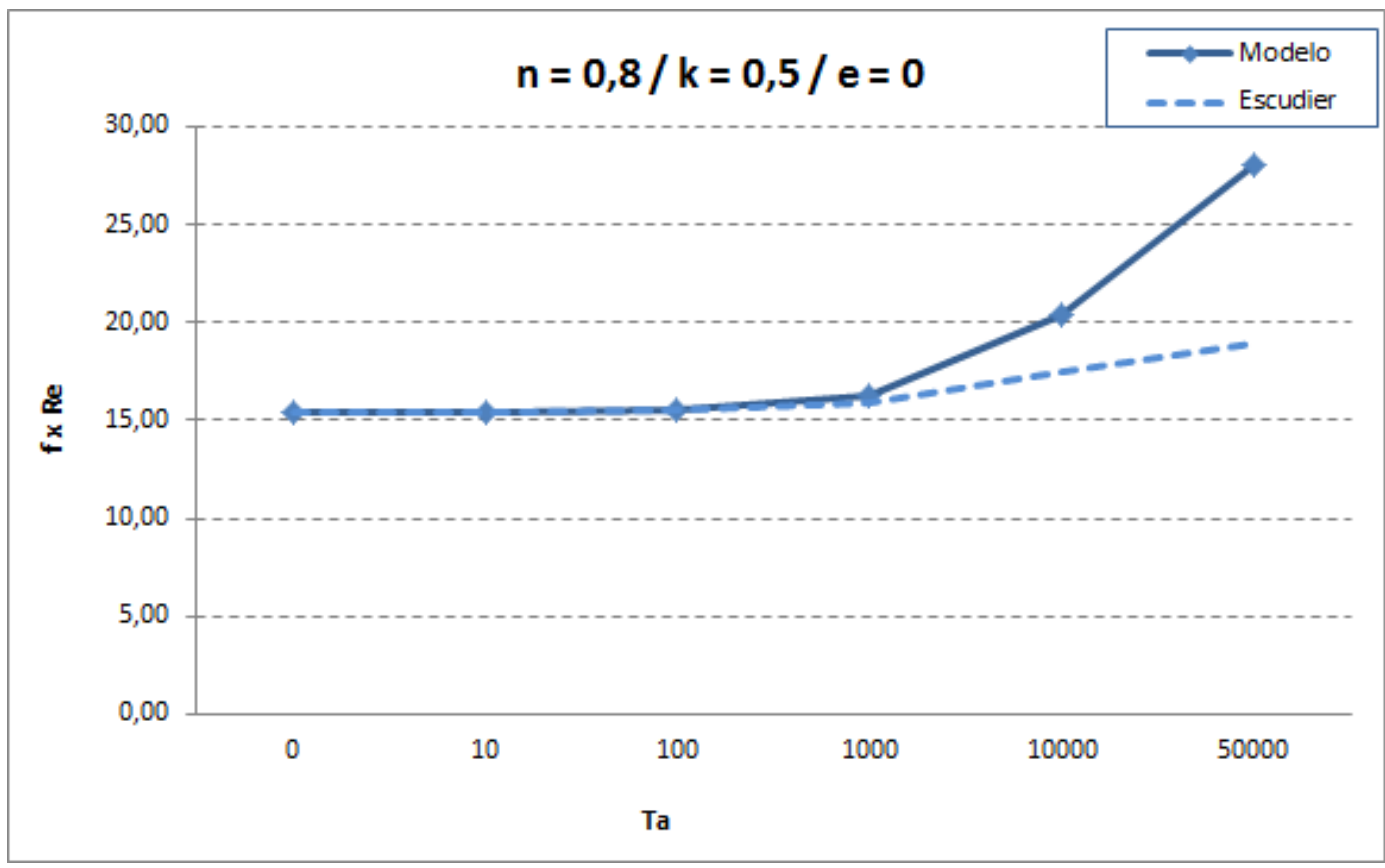

Figura 29 - Variação da relação $f$. Re com Ta em anular concêntrico 


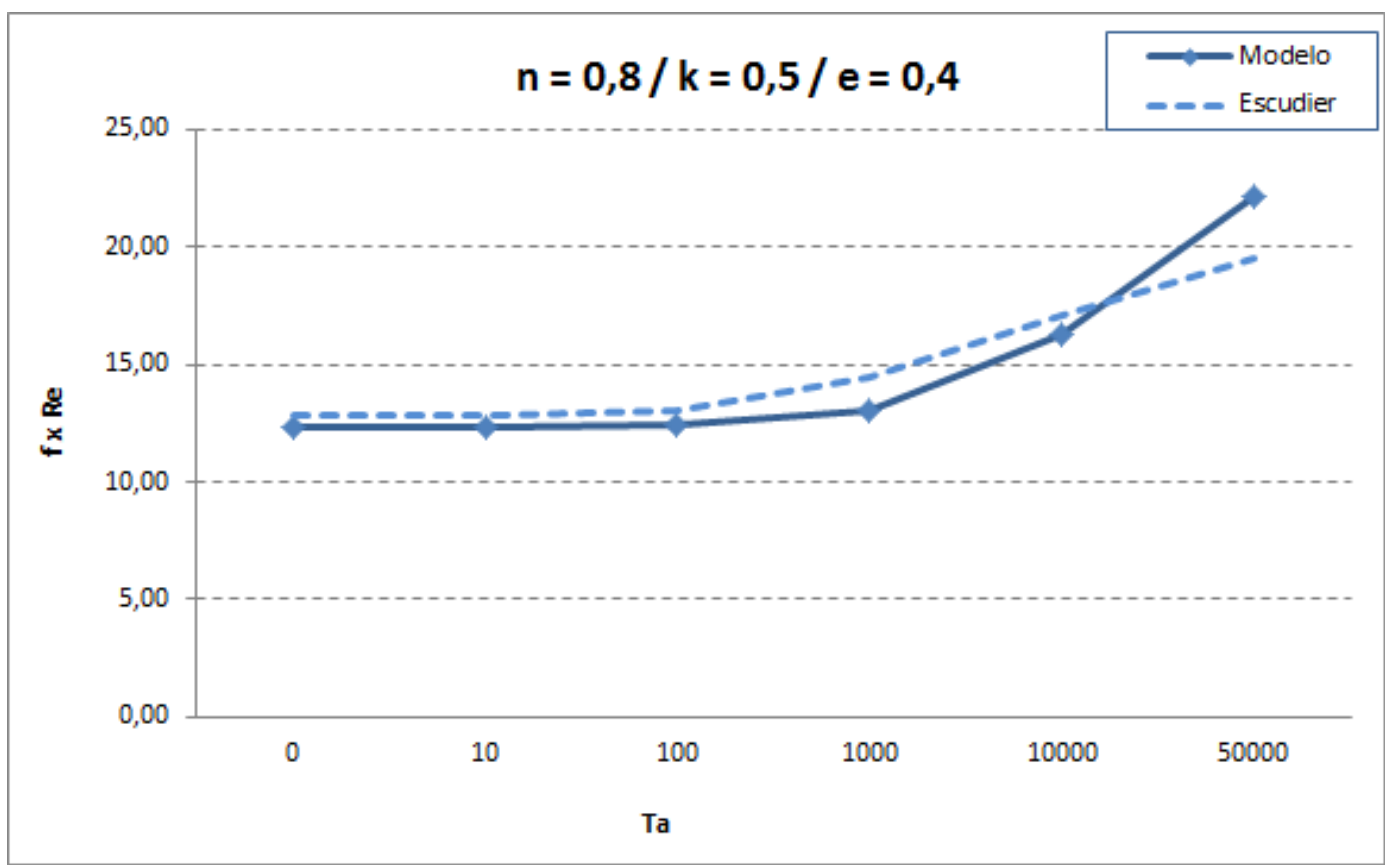

Figura 30 - Variação da relação $f$. Re com Ta e excentridade constante $(e=0,4)$

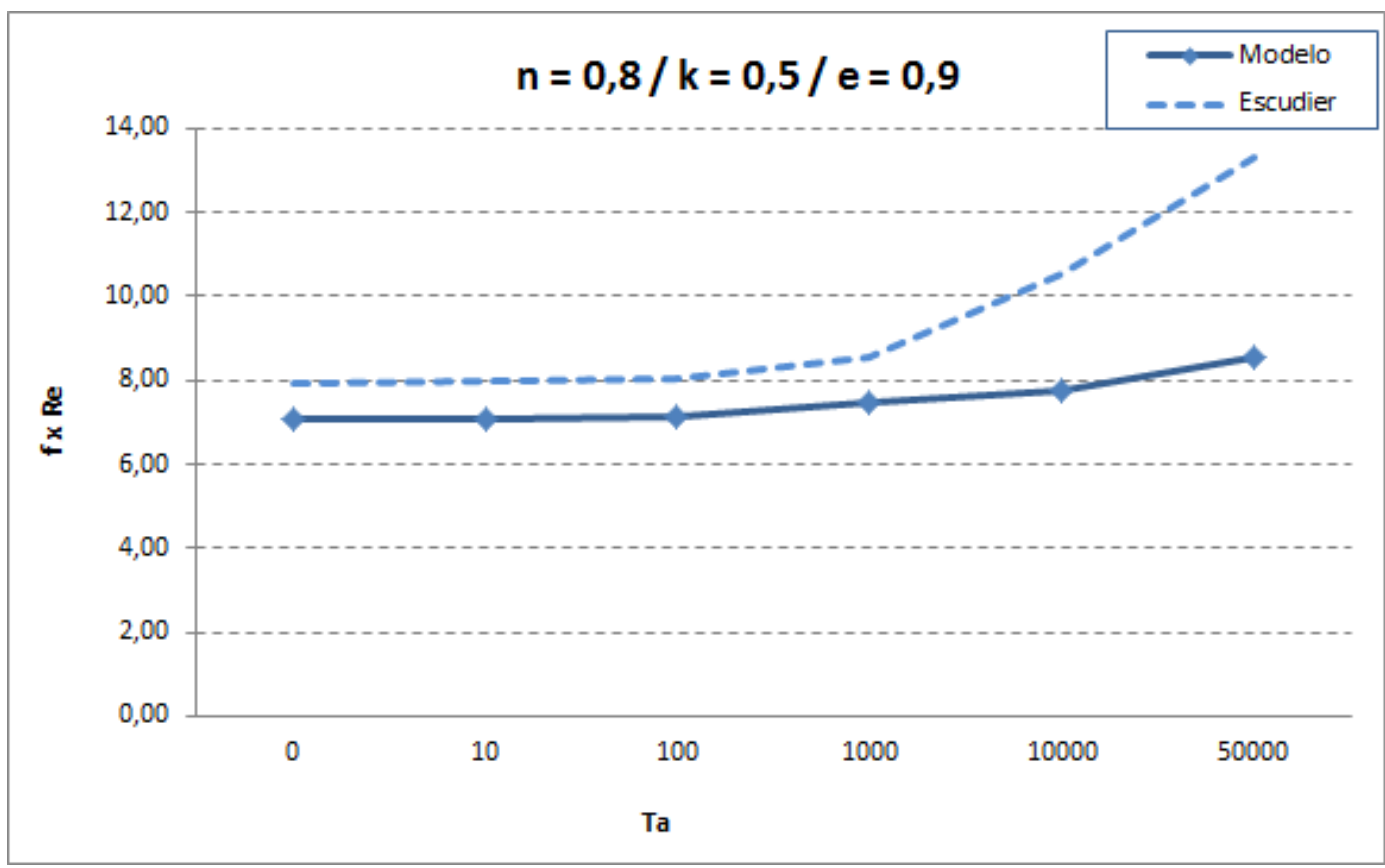

Figura 31 - Variação da relação $f$. Re com Ta e excentridade constante $(e=0,9)$

A Figura 32 apresenta a influência da rotação do cilindro interno para fluidos não Newtonianos com diferentes índices de comportamento do fluido $(n)$. $\mathrm{O}$ aumento do produto $f$.Re com o aumento do número de Taylor é resultado do aparecimento de zonas de recirculação, conforme discutido nas figuras anteriores. 
Entretanto, um comportamento de redução do produto $f$. Re é observado quando tem-se alto valor do número de Taylor para índice de comportamento do fluido 0,5. Isto ocorre devido ao desaparecimento de zonas recirculação no espaço anular próximo à parede do cilindro externo e a redução da viscosidade devido à alta taxa de cisalhamento. Estes resultados estão de acordo com a solução obtida por Escudier, mesmo nas regiões de alta rotação do cilindro interno onde se observa perda de precisão do modelo proposto.

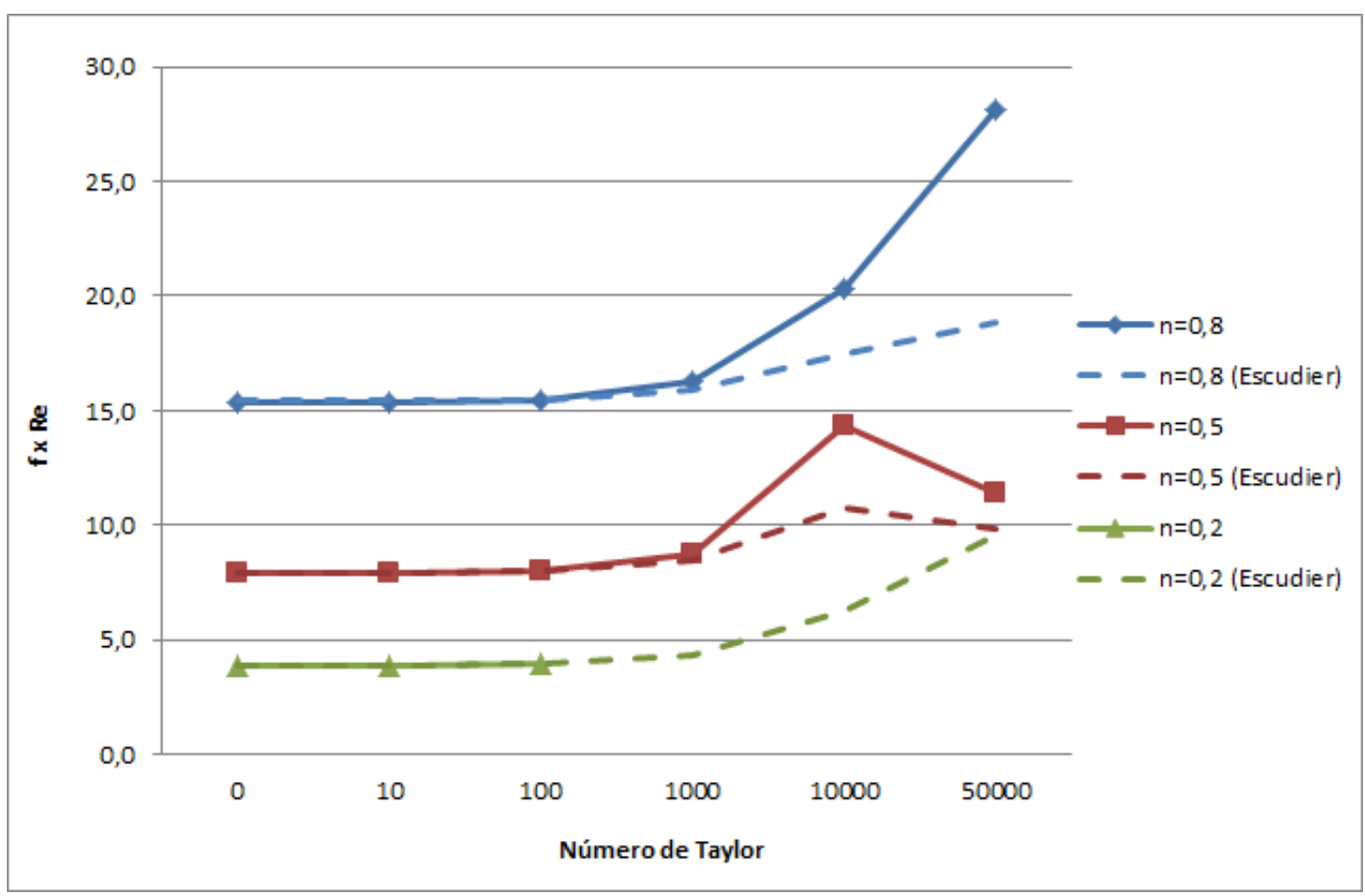

Figura 32 - Variação da relação $f$. Re com Ta para fluidos não Newtonianos em espaço anular concêntrico e mesma razão de raios $(k=0,5)$ 


\section{4 \\ Considerações Finais}

A determinação da perda de carga no escoamento de fluidos de perfuração em anulares de poço é de extrema importância para o projeto da operação. $\mathrm{O}$ estudo teórico-numérico deste escoamento é bastante complexo, já que o campo de velocidade é tridimensional e o comportamento não Newtoniano dos fluidos de perfuração aumenta ainda mais as não linearidades do problema.

O presente trabalho apresenta um modelo simplificado baseado na teoria da Lubrificação e Viscosidade Newtoniana Equivalente para estudar o escoamento em anulares com rotação da coluna.

A fim de se avaliar o erro numérico obtido pelo método da Viscosidade Newtoniana Equivalente, comparou-se o modelo proposto com a solução analítica obtida por Bird [26] para o escoamento de um fluido não Newtoniano em espaço anular concêntrico sem rotação do cilindro interno. O resultado obtido apresenta um erro médio não significativo, que aumenta à medida que o fluido se afasta do comportamento Newtoniano. Este erro médio pode ser atribuído à utilização do método da Viscosidade Newtoniana Equivalente.

Posteriormente, a validação do modelo proposto foi realizada através de comparação com a solução numérica de Escudier [16] para o escoamento laminar completamente desenvolvido de um fluido Power-law no espaço anular com excentricidade constante ao longo do escoamento axial. Os resultados obtidos pelo modelo para o escoamento sem rotação do cilindro interno estão de acordo com a solução proposta por Escudier, e mostram que o produto $f$. Re diminui com o aumento da excentricidade. Este fenômeno é devido à diminuição do espaço de folga radial mínimo, com o escoamento da maior parte do fluido na região de maior folga radial.

Por último, compararam-se os resultados do modelo proposto com a solução numérica proposta por Escudier para o escoamento no espaço anular com rotação do cilindro interno. A inclusão do efeito da rotação do cilindro interno resultou em 
problemas de convergência do modelo, dependendo da velocidade de rotação do cilindro interno e do afastamento do comportamento Newtoniano do fluido. Os estudos mostraram que a utilização do modelo proposto é favorável para fluidos com índice de comportamento do fluido 0,8 e $T a \leq 1000$. Nesses casos, o erro numérico observado é pequeno e a utilização de uma solução de baixo custo computacional é bastante vantajosa. Para fluidos muito afastados do comportamento Newtoniano o modelo não consegue convergir mesmo que para baixas velocidades de rotação do cilindro interno $(n=0,2$ e $T a=10)$.

Analisando-se os resultados obtidos pelo modelo é possível observar o mesmo comportamento de redução do produto $f . R e$ com o aumento da excentricidade. Além disso, o aumento da velocidade de rotação do cilindro interno juntamente com o aumento da excentricidade irá resultar no aumento do produto $f$. Re devido ao aparecimento de zonas de recirculação na região de maior folga radial.

A grande vantagem da metodologia empregada é o pequeno custo computacional necessário para solução do problema em relação aos diversos trabalhos publicados na literatura, independentemente do comportamento reológico do fluido.

O conhecimento obtido neste trabalho também pode ser ampliado incluindose uma geometria anular excêntrica tridimensional. Desta forma, o modelo desenvolvido possibilitará uma avaliação mais próxima da realidade do fenômeno de flambagem da coluna de perfuração presente na perfuração de poços direcionais.

Outra proposta de melhoria ao modelo desenvolvido é a utilização de outro critério de convergência a fim de se aumentar a precisão dos resultados obtidos. Um modelo baseado na vazão volumétrica pode em alguns casos convergir antes de ocorrer a convergência da viscosidade. 


\section{5}

\section{Referências Bibliográficas}

1 http://www.petroleoetc.com.br

2 ROCHA, L. A. S.; AZEVEDO, C. T. Projetos de Poços de Petróleo. Rio de Janeiro: Editora Interciência, 2007.

3 ROCHA, L. A. S. et al. Perfuração Direcional. Rio de Janeiro: Editora Interciência, 2006.

4 THOMAS, J. E. (Org.). Fundamentos da Engenharia do Petróleo. 2. ed. Rio de Janeiro: Editora Interciência, 2001. 271p

5 RIBEIRO, P. R. Engenharia de Perfuração. Unicamp. Faculdade de Engenharia Mecânica. Departamento de Engenharia de Petróleo. 2000.

6 http://www.tecnicodepetroleo.ufpr.br/apostilas/engenheiro do petroleo /perfuraçoes.PDF

7 VAUGHN, R. D. Axial Laminar Flow of Non-Newtonian Fluids in Narrow Eccentric Annuli. Society of Petroleum Engineers, SPE 1138, 1965.

$8 \mathrm{IYOHO}$, A. W.; AZAR, J. J. An Accurate Slot-Flow Model for NonNewtonian Fluid Flow Through Eccentric Annuli. Society of Petroleum Engineers, SPE 9447, October 1981.

9 PINHO, F. T.; WHITELAW, J. H. Flow of Non-Newtonian Fluids in a Pipe. Journal of Non-Newtonian Fluid Mechanics, Netherlands, v. 34, p. 129-144, 1990.

10 UNER, D.; OZGEN, C.; TOSUN, I. Flow of a Power-Law Fluid in an Eccentric Annulus. Society of Petroleum Engineers, SPE 17002. September, 1989.

11 LUO, Y.; PEDEN, J.M. Flow of Non-Newtonian Fluids Through Eccentric Annuli. Society of Petroleum Engineers, SPE 16692. February 1990.

12 CUI, H.; LIU, X. Research on Helical Flow of Non-Newtonian Fluids in Eccentric Annuli. Society of Petroleum Engineers, SPE 29940. Beijing, November 1995.

13 SIGINER, D. A.; BAKHTIYAROV, S. I. Flow of drilling fluids in eccentric annuli. Journal of Non-Newtonian Fluid Mechanics, v. 78, p. 119-132, 1998.

14 KUTATELADZE, S. S.; POPOV, V. I.; KHABAKHPASHEVA, E. M. The hydrodynamics of fluids of variable viscosity (in Russian). J. Appl. Mech. Technol. Phys., v. 1, p. 45-49, 1966. 
15 ESCUDIER, M. P. et al. Effects of inner cylinder rotation on laminar flow of a Newtonian fluid through an eccentric annulus. International Journal of Heat and Fluid Flow, v. 21, p. 92-103, 1999.

16 ESCUDIER, M. P.; OLIVEIRA, P. J.; PINHO, F. T. Fully developed laminar flow of purely viscous non-Newtonian liquids through annuli, including the effects of eccentricity and inner-cylinder rotation. International Journal of Heat and Fluid Flow, v. 23, p. 52-73, 2002.

17 HEMPHILL, T.; RAVI, K. Calculation of Drillpipe Rotation Effects on Fluids in Axial Flow. Society of Petroleum Engineers, SPE 97158. Dallas, 2005.

18 HEMPHILL, T.; RAVI, K. Pipe Rotation and Hole Cleaning in an Eccentric Annulus. Society of Petroleum Engineers, IADC/SPE 99150. Miami, February 2006.

19 KELESSIDIS, V.C. et al. Optimal determination of rheological parameters for Herschel-Bulkley drilling fluids and impact on pressure drop, velocity profiles and penetration rates during drilling. Journal of Petroleum Science and Engineering, v. 53, p. 203224, 2006.

20 PINA, E. P. F.; CARVALHO, M. S. Three-Dimensional Flow of a Newtonian Liquid Through an Annular Space with Axially Varying Eccentricity. Journal of Fluids Engineering, v. 128, March 2006.

21 AHMED, R.; MISKA, S. Experimental Study and Modeling of Yield Power-Law Fluid Flow in Annuli with Drillpipe Rotation. Society of Petroleum Engineers, IADC/SPE 112604. Orlando, March 2008.

22 MORONI, N.; RAVI, K.; SAIRAM, P. Pipe Rotation Improves Hole Cleaning and Cement-Slurry Placement: Mathematical Modeling and Field Validation. Society of Petroleum Engineers, SPE 124726. Aberdeen, September 2009.

23 ALEXANDRE, B. B.; CARVALHO, M. S. Escoamento de Fluido não Newtoniano em Espaço Anular com Excentricidade Variável. Dissertação de mestrado. Pontifícia Universidade Católica, PUC-Rio. Setembro 2009.

24 MACHADO, J. C. Fundamentos e Classificação de Fluidos Viscosos. Reologia e Escoamento de Fluidos - Ênfase na Indústria do Petróleo. Editora Interciência. Rio de Janeiro, 2002. p. 1-40.

25 BROYER, E.; GUTFINGER, C.; TADMOR, Z. Evaluating flows of non-Newtonian fluids by the method of equivalent Newtonian viscosity. AIChE Journal, New York, v.21, no 1, p. 198-200, 1975.

26 BIRD, R. B.; STEWART, W. E.; LIGHTFOOT, E. N. Transport Phenomena. 2nd edition. John Wiley \& Sons, Inc, 2002.

27 FOX, R. W.; MCDONALD, A. T.; PRITCHARD, P. J. Introdução à Mecânica dos Fluidos. 6. Ed. Rio de Janeiro: Editora LTC, 2006. 